\title{
MYB oncoproteins: emerging players and potential therapeutic targets in human cancer
}

\author{
Ylenia Cicirò ${ }^{1}$ and Arturo Sala (D)
}

\begin{abstract}
MYB transcription factors are highly conserved from plants to vertebrates, indicating that their functions embrace fundamental mechanisms in the biology of cells and organisms. In humans, the MYB gene family is composed of three members: MYB, MYBL1 and MYBL2, encoding the transcription factors MYB, MYBL1, and MYBL2 (also known as c-MYB, $A-M Y B$, and B-MYB), respectively. A truncated version of MYB, the prototype member of the MYB family, was originally identified as the product of the retroviral oncogene $v$-myb, which causes leukaemia in birds. This led to the hypothesis that aberrant activation of vertebrate MYB could also cause cancer. Despite more than three decades have elapsed since the isolation of v-myb, only recently investigators were able to detect MYB genes rearrangements and mutations, smoking gun evidence of the involvement of MYB family members in human cancer. In this review, we will highlight studies linking the activity of MYB family members to human malignancies and experimental therapeutic interventions tailored for MYB-expressing cancers.
\end{abstract}

\section{Introduction}

Vertebrate $M Y B$ genes encode transcription factors related to the $v-m y b$ oncogene, the transforming gene of avian retroviruses causing myelomas and lymphomas in birds $^{1,2}$. AMV was originally identified as a virus that induces a disease in chickens similar to acute myelogenous leukaemia in humans ${ }^{3}$. The $v-m y b^{A M V}$ oncogene product, a $45 \mathrm{kDa}$ protein, was proved to be a truncated version of vertebrate MYB, the $75 \mathrm{kDa}$ product of the proto-oncogene $M Y B$, mainly expressed in haematopoietic tissues ${ }^{4,5}$. The $v-m y b$ oncogene was also found fused to a second oncogene, $v$-ets, in the E26 retrovirus that cause avian erythroblastosis ${ }^{6}$. Invertebrates carry only one $M Y B$ gene which, from a phylogenetical and functional point of view, is equivalent to vertebrate $M Y B L 2$, suggesting that this is the most ancient member of the family ${ }^{7,8}$. There is no homologue of the $M Y B$ gene in nematodes, although distantly related genes, such as $C d c 5$ and $S N A P c$, have been identified in Caenorhabditis elegans ${ }^{9,10}$.

\footnotetext{
Correspondence: Arturo Sala (Arturo.sala@brunel.ac.uk)

${ }^{1}$ Department of Life Sciences, Centre for Inflammation Research and

Translational Medicine, Brunel University London, UB8 3PH Uxbridge, UK
}

In humans and other mammals, the transcription factor MYB (encoded by $M Y B$ ) is the prototype member of the family, which includes MYBL1 (encoded by MYBL1) and MYBL2 (encoded by $M Y B L 2)^{11}$. Although similar in structure, the different MYB proteins interact with unique co-factors and their expression is often nonoverlapping, suggesting that they might have distinct biological roles (Fig. 1) $)^{12-15}$.

\section{MYB proteins structure and identification of target genes}

MYB proteins contain a highly conserved helix-turnhelix (HTH) DNA-binding domain (DBD) at the N-terminus, encompassing three tandem repeated domains of $\sim 50$ amino acids containing tryptophan named R1, R2, and $\mathrm{R} 3{ }^{16}$; a conserved $\mathrm{C}$-terminal negative regulatory domain (NRD); a trans-activating domain (TAD) in the central portion of the protein. The latter includes an acidic region and a heptad leucine-zipper repeat only present in MYB and MYBL1 (Fig. 1) ${ }^{9}$.

All MYB family members recognise and bind the same DNA consensus sequence [PyAAC(G/T)G] to transactivate gene expression. This motif, firstly identified by the 
MYB
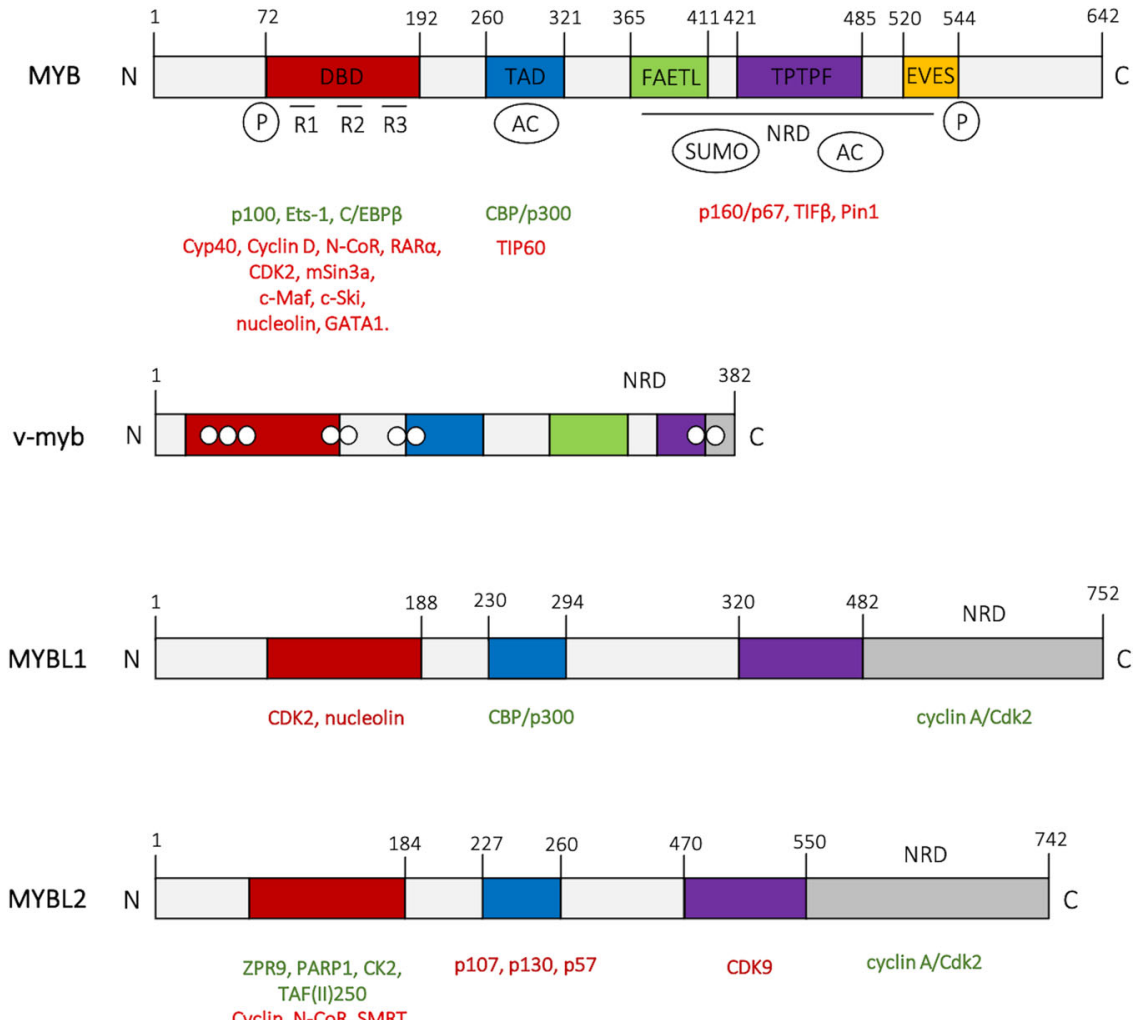

Fig. 1 MYB family members' protein structures. The $\mathrm{V}$-myb DNA-binding domain is equivalent to amino acids $72-192$ of MYB, except the introduction of four point mutations ( $191 \mathrm{~N}, \mathrm{~L} 106 \mathrm{H}, \mathrm{V} 117 \mathrm{D}$, and $1181 \mathrm{~V})$ and the addition of six amino acids in N-terminal region derived from the retroviral Gag polyprotein ${ }^{187}$. The white dots on AMV v-myb structure indicate point mutations important for the ability of v-myb to transform cells $^{188}$. MYB co-activators are listed in green and the co-repressors are listed in red. The DNA-binding domain (DBD) is comprised of three repeats (R1, R2, and R3). It is the binding site for a number of proteins including p100, PARP, c-Ski, N-CoR, RAR, Cyp40, C/EMPbeta, SMRT, and mSin3A, as depicted; the central transactivation domain (TAD) is the interaction site for CBP/p300; the negative regulatory domain (NRD) extends from the FAETL motif to the EVES peptide sequence (involved in intramolecular and intermolecular protein-protein interactions) and includes the binding sites for p160/p67, Pin1, and TIF1 beta ${ }^{150,189-193}$. The post-translational modifications include phosphorylation (P), acetylation (AC), and sumoylation $(\mathrm{SUMO})^{194-197}$.

Klempnauer group using DNA footprinting assays, is known as the canonical MYB-binding site (MBS) $)^{17}$. The sequence was later confirmed to be present, and bound by $\mathrm{v}$-myb, in the promoter region of the first MYB-target gene identified in vertebrates, mim- $1^{18}$. With the development of more advanced genomic technologies, different groups attempted the identification of MYB target genes at the global level. The Ness team found the c-MYB protein bound to over 10,000 promoters in the cancer breast cell line MCF-7, and validated known MYB target genes involved in the cell cycle, such as $M Y C$ and CCNB1, or identified new MYB target genes involved in stemness and transcription control such as JUN, KLF4, NANOG and $S N D 1^{19}$. Another study by the Gonda lab identified genes regulated by MYB in mouse myeloid progenitor cells. This study not only confirmed that MYB positively regulates promoters of key cell proliferation genes, such as $M y c$, but it can also work as a transcriptional repressor. Indeed, several key regulators of myeloid differentiation such as Runx1, Pu.1, Junb and Cebp were strongly suppressed by exogenous expression of $M Y B$, suggesting a mechanism used by the transcription factor to suppress differentiation and promote self-renewal ${ }^{20}$. A selection of $M Y B$ target genes that have been shown to mediate physiological functions in normal or disease contexts is shown in Table 1.

The transcriptional activity of MYB proteins is regulated either positively or negatively by co-factors; cellular proteins physically interacting with the different MYB family members are indicated under their protein structures in Fig. 1. Structure-function relationships have been largely inferred by studying the prototype member of the family, MYB (c-MYB). For example, the TAD domain confers transactivating activity to MYB by recruiting CREB-binding domain protein (CBP) and $\mathrm{p} 300^{21,22}$. The CAAT enhancer-binding protein (C/EBP) family member NF-M cooperates with MYB in transcriptionally activating the mim-1 promoter through an adjacent 
Table 1 Selected MYB target genes.

\begin{tabular}{|c|c|c|c|}
\hline Target gene & Protein & MYB member & References \\
\hline ATR & Ataxia telangiectasia Rad3-related protein & MYB & 43 \\
\hline$B C L 2$ & B-cell lymphoma 2 & $\begin{array}{l}\text { v-Myb, MYBL2, } \\
\text { MYB }\end{array}$ & $137,198,199$ \\
\hline BIRC5 & Survivin & MYBL2, MYB & $136,200,201$ \\
\hline CCNA2 & Cyclin A2 & MYBL2 & 149,202 \\
\hline CCNB1 & Cyclin B1 & MYB & $19,38,203$ \\
\hline CCND1 & Cyclin D1 & MYBL2 & 131,204 \\
\hline CCNE1 & Cyclin E1 & MYB & 205,206 \\
\hline CD34 & Haematopoietic progenitor cell antigen CD34 & MYB & $207-209$ \\
\hline CDK1 & Cyclin-dependent kinase 1 & MYBL2, MYB & $42,149,202$ \\
\hline CDK2 & Cyclin-dependent kinase 2 & MYBL2 & 210 \\
\hline CDK6 & Cyclin-dependent kinase 6 & MYB & 211 \\
\hline CLU & Apolipoprotein J/Clusterin & MYBL2 & $132,134,212$ \\
\hline CXCR4 & C-X-C chemokine receptor type 4 & v-Myb, MYB & 19,213 \\
\hline IGFIR & Insulin-like growth factor 1 receptor & MYB & $106,107,109,113$ \\
\hline KIT & (c-)KIT/CD117 & MYB & $119,214,215$ \\
\hline MIM1 & Mitochondrial import protein 1 & v-Myb, MYB & $18,216,217$ \\
\hline MYC & (c-)MYC & MYBL2, MYB & $19,20,138,210,218$ \\
\hline NCAPH & Non-SMC Condensin I Complex Subunit H & MYBL2 & 169 \\
\hline PLK1 & Polo-like kinase 1 & MYBL2 & $157,159,202$ \\
\hline TAL1 & T-cell acute lymphocytic leukaemia protein 1 & MYB & 27 \\
\hline VEGF & Vascular endothelial growth factor & MYB & 118 \\
\hline
\end{tabular}

DNA-binding site and it is also co-activated by CBP in a Ras-dependent manner, suggesting that CBP might work by functionally linking MYB and NF- $\mathrm{M}^{22}$. Indeed, NF-M has been shown to affect the MYB-C/EBP interaction by disrupting the $\mathrm{N}$-terminal region within the repeat domain R1 (amino acids 47-71), enhancing MYB oncogenic activity ${ }^{23}$.

MYB can cooperate, cross-regulate and compete with other transcription factors, such as members of the C/EBP family, the ETS family, and GATA1 ${ }^{24-26}$. Recently, it has been shown that in ALL patients aberrant recruitment of the histone acetyl transferase $\mathrm{CBP} / \mathrm{p} 300$ by MYB in the enhancer region of the protooncogene $T A L 1$ occurs via the formation of de novo MYB-binding elements ${ }^{27}$.

\section{Alterations of MYB family genes in human cancer and experimental therapeutic approaches}

$M Y B$ family members are often aberrantly expressed in human cancers, suggesting that they could be important for tumour initiation and/or maintenance. Since MYB proteins are essential for key cellular processes such as growth, differentiation and survival, it is likely that genomic mutations or alterations of gene expression might contribute to oncogenesis. Broadly expressed transcription factors are considered unsuitable therapeutic targets since their inactivation or downregulation could be detrimental to organism homoeostasis. Furthermore, it is inherently difficult to block the interaction of transcription factors with DNA using small molecules. Despite these caveats, therapeutic approaches aiming at inhibiting MYB oncoproteins, or their target genes, in cancer are under investigation in preclinical and clinical studies.

In the following paragraphs, we discuss studies in which $M Y B$ family members have been implicated in forms of human cancer. We also highlight laboratory experiments, or clinical trials, in which $M Y B$, or $M Y B$-regulated genes, have been targeted for therapeutic purposes.

\section{MYB}

Disruption of $M Y B$ causes embryonic lethality due to the failure of foetal hepatic haematopoiesis ${ }^{28}$. The key role 
of the $M Y B$ gene product in mammalian haematopoiesis is also indicated by its ability to regulate the expression of foetal haemoglobin and requirement for the maturation of $\mathrm{T}$ and $\mathrm{B}$ lymphocytes ${ }^{29-32}$. Although prevalently expressed in haematopoietic cells, MYB expression is detected also in neural tissues, as well as in colonic crypts and breast cells ${ }^{33-37}$.

MYB, similarly to the ubiquitous member of the family MYBL2, regulates cyclin-dependent kinases (Cdks) expression and activity, essential for cell duplication ${ }^{38,39}$. MYB autoregulates its own expression and is engaged in positive and negative regulatory loops with cyclins and Cdks, in both the G1 and G2 phases of the cell cycle ${ }^{38,40-42}$.

\section{MYB alterations in cancer}

Genetic mutations and augmented expression of $M Y B$ have been firstly noted in leukaemic cells, and only relatively recently in solid cancers. Overexpression of wild type $M Y B$ is insufficient for full transformation of human epithelial cells, supporting the hypothesis that it promotes tumourigenesis only in combination with additional genetic alterations ${ }^{43}$.

The first recurrent genomic rearrangements of the $M Y B$ locus were evidenced in acute $\mathrm{T}$ cell leukaemia, in which $M Y B$ overexpression is caused by gene duplication or translocation, juxtaposing strong enhancers from other genomic locations ${ }^{44}$. Summarising the information present in literature, it is possible to group $M Y B$ oncogenic alterations into three classes: overexpression, fusion with partner genes, and ectopic binding of the MYB oncoprotein to enhancer sequences caused by somatic mutations (i.e. TAL1 enhancer ${ }^{27}$ ). MYB gene amplification and overexpression have been observed in acute myeloid leukaemia (AML), non-Hodgkin lymphoma, colorectal cancer, and breast cancer,45-48. Fusion with partner genes is mainly observed in solid tumours, as discussed in detail in the following sections.

$M Y B$ genomic alterations have been detected in multiple forms of human cancer, suggesting a causative role. Therefore, numerous studies have been conducted in which inhibition of $M Y B$, or of its downstream genes, has been used as a potential therapeutic strategy. Preclinical studies and actionable MYB target genes are summarised in Table 2.

MYB and leukaemia In a cluster of acute lymphoblastic leukaemia (ALL) patients, mutations of the TAL1 enhancer create ex-novo MYB-binding sites. The leukaemias arising in these patients show MYB-dependency consequential to the aberrant activation of the TAL1 oncogene by $\mathrm{MYB}^{27}$. Through genomic screening of an independent set of 107 individuals with T cell ALL (TALL) and 12 T-ALL cell lines, Lahortiga et al. detected duplication of MYB in 9 of 107 (8.4\%) cases and in five
Table 2 Preclinical and clinical therapeutic strategies based on inhibition of MYB or actionable MYBtarget genes.

\begin{tabular}{|c|c|c|c|}
\hline Treatment & Target & Cancer type & References \\
\hline $\begin{array}{l}\text { AT7519, BE-09- } \\
\text { LN53 (CDKi) }\end{array}$ & CDKs & $E R+B C$ & 90 \\
\hline ATRA & MYB & ACC & 111 \\
\hline Celastrol & $\begin{array}{l}\text { MYB-C/ } \\
\text { EBPß-p300 }\end{array}$ & AML & 67 \\
\hline Mebendazol & MYB & AML & 69 \\
\hline $\mathrm{miR}-200 \mathrm{~b} / \mathrm{c}$ & EMT markers & $E R+B C$ & 94 \\
\hline Monensin A & MYB & $\mathrm{AML}, \mathrm{ACC}$ & 110 \\
\hline MYBMIM & MYB:CBP/p300 & AML & 71 \\
\hline $\begin{array}{l}\text { Naphthol AS-E } \\
\text { phosphate }\end{array}$ & MYB-C/KIX(p300) & Leukaemia & 68 \\
\hline Plumbagin & MYB/p300 & AML & 70 \\
\hline TetMYB vaccine & MYB & CRC, ACC & 81 \\
\hline VX-970 & ATR & ACC & 43 \\
\hline Figitumumab & IGFR & ACC & 109 \\
\hline Linsitinib & IGFR & ACC & 112 \\
\hline
\end{tabular}

ATRA all trans retinoic acid, ACC adenoid cystic carcinoma, $A M L$ acute myeloid leukaemia, $C D K s$ cyclin-dependent kinases, $C R C$ colorectal cancer, EMT epithelial mesenchymal transition, $E R+B C$ oestrogen receptor positive breast cancer.

different cell lines ${ }^{49}$. The flanking genes $H B S 1 L$ and $A H I 1$ were duplicated in some patients, but the commonly duplicated region covered only the $M Y B$ gene. The duplication is associated with a threefold increase in $M Y B$ expression, and its knockdown initiates $\mathrm{T}$ cell differentiation. Thus, $M Y B$ duplications may be leukaemogenic in a subset of T-ALL patients ${ }^{49}$.

In acute basophilic leukaemia (ABL) the MYB locus is fused to another gene encoding the transcription factor GATA1. This rare subtype of acute myeloblastic leukaemia is characterised by the $\mathrm{t}(\mathrm{X} ; 6)(\mathrm{p} 11 ; \mathrm{q} 23)$ translocation, leading to decrease or loss of GATA1 (located on chromosome X) expression $^{50}$. Mice transgenically expressing the MYB-GATA1 fusion develop myelodysplasia and leukaemia when endogenous, wild-type GATA1 expression is concurrently downregulated ${ }^{51}$. Ducassou and coworkers showed that the fusion promotes not only haematopoietic progenitor cell self-renewal, but also induces a bias toward granulocytic differentiation, consequently to sensitisation towards NGF- and IL-33-induced differentiation ${ }^{52}$. The skewing towards basophilic differentiation was confirmed in primary human CD34-positive stem/progenitor cells, where the basophilic markers CD203c and FceRI were activated after MYB-GATA1 expression. In vivo experiments using NSG mice led to conclusive evidence that basophilic differentiation is a 
direct consequence of MYB-GATA1 expression, rather than loss of endogenous GATA1 ${ }^{52}$. The increased responsiveness to IL-33 could contribute to the leukaemic phenotype, as previously observed in other myeloproliferative malignancies ${ }^{53}$. Thus, MYB-GATA1 might promote cell growth, self-renewal and leukaemic transformation of basophilic progenitor cells ${ }^{52}$.

A case report described a Philadelphia-negative myeloproliferative neoplasm (Ph-MPN) with an uncommonly rapid leukaemic progression, linked to JAK2 ${ }^{\mathrm{V} 617 \mathrm{~F}}$ mutation. This primary myelofibrosis (PMF)-patient developed a peculiar chromosomal rearrangement resulting in a fusion involving EWSR1 and $M Y B$. There are only a few cases reporting fusion of EWSR1 in leukaemia, whereas it is common in soft tissue sarcoma ${ }^{54-56}$. EWSR1 is a FET (FUS, EWS, TAF15) family member whose function is to regulate transcription and mRNA splicing ${ }^{57}$. Therefore, it seems reasonable to speculate that the EWSR1-MYB fusion could lead to dysregulated $M Y B$ transcriptional activity. Indeed, expression of the MYB target gene $B C L 2$ was deregulated in EWSR1-MYB positive PMF, suggesting that molecular alterations involving $M Y B$ could increase disease risk in PMF patients ${ }^{58}$.

AML is the most common form of acute leukaemia in adults $^{59}$. Although recent advances in genomic characterisations have shed some light on the molecular patterns involved in this cancer, the 5 -year survival rate is $<70 \%$ in children and $35 \%$ in adults ${ }^{60,61}$.

AML is a heterogeneous disease, often characterised by the presence of gene fusions or recurrent mutations in a set of driver genes ${ }^{62}$. Genomic rearrangements involving the $M L L$ gene, such as $M L L-A F 4 \mathrm{t}(4 ; 11)(\mathrm{q} 21 ; \mathrm{q} 23)$; $M L L-A F 9 ; \quad \mathrm{t}(9 ; 11)(\mathrm{p} 22 ; \mathrm{q} 23) ; \quad M L L-E N L ; \mathrm{t}(11 ; 19)(\mathrm{q} 23 ;$ p13.3); $M L L-A F 10 \mathrm{t}(10 ; 11)(\mathrm{p} 12 ; \mathrm{q} 23)$ or $M L L-A F 6 \mathrm{t}$ $(6 ; 11)(\mathrm{q} 27 ; \mathrm{q} 23)$ are associated with a very aggressive form of leukaemia ${ }^{63,64}$. MYB has been shown to be a key downstream effector of MLL fusion oncoproteins, suggesting that it could be a target for therapeutic interventions ${ }^{65}$. Since, as mentioned before, targeting transcription factors with small molecule inhibitors is difficult, the focus has been directed towards proteins that work as co-activators in the MYB network. p300 is a MYB transcriptional co-activator, required for leukaemogenesis $^{66}$. The small molecule inhibitor Celastrol, a triterpenoid, was used to disrupt the $\mathrm{MYB} / \mathrm{p} 300$ interaction, therefore interrupting MYB signalling in leukaemic cells. Celastrol did not change $M Y B$ expression but inhibited the interaction of the transactivation domain of MYB with the KIX domain of p300. Accordingly, Celastrol strongly inhibited MYB-dependent transcriptional activation of target genes. Celastrol enhanced survival of mice transplanted with patient-derived HoxA9/Meis1-driven AML, confirming that targeting MYB transcription function could be an effective strategy in this leukaemia ${ }^{67}$. Another compound used to disrupt the interaction between MYB and p300, Naphthol AS-E phosphate, inhibited the expression of the $M Y B$ gene itself, as well as that of several MYB-target genes, inducing myeloid differentiation and apoptosis ${ }^{68}$. The negative effect of Naphthol ASE phosphate on $M Y B$ gene expression could be a consequence of the block of $M Y B$ gene autoregulation. Nicolaides et al. showed that human $M Y B$ maintains high levels of its expression through an autoregulatory mechanism involving MYB-binding sites in the $5^{\prime}$ flanking region of the $M Y B$ gene itself ${ }^{41}$.

The anti-helminth agent mebendazole exhibited anticancer activity in AML human cell lines by interfering with MYB activity. Short-term exposure to the drug induced changes in the expression level of MYB-regulated genes in cells expressing the MLL-AF9 fusion oncoprotein ${ }^{69}$. Expression of the MYB oncoprotein was drastically reduced in the presence of low concentrations of the drug in all cell lines analysed, whereas MYB mRNA levels were only reduced after exposure to very high mebendazole concentrations, and only in a few of the cell lines. This suggested that the drug acts mainly at the protein level. Indeed, inhibition of the proteasome reversed MYB protein loss, demonstrating that mebendazole causes proteasomal degradation of MYB by interfering with the heat shock protein 70 (HSP70) chaperone system. Importantly, mebendazole impaired AML cancer progression in vivo ${ }^{69}$.

5-hydroxy-2-methyl-1,4-naphthoquinone (also known as plumbagin) has been shown to target the transcriptionalactivating domain (TAD) of MYB. By using the MYB TAD fused to the Gal4 DBD, the Klempnauer group observed that plumbagin inhibits transcription of a reporter gene containing GAL4-binding sites. Increasing the dosage of ectopically expressed p300, progressively antagonised the effect of plumbagin, demonstrating that the drug interfered with the p300-MYB interaction in AML cells ${ }^{70}$.

Recently, a peptidomimetic approach to block the activity of MYB was developed by designing an inhibitory peptide called MYBMIM. The MYBMIM inhibitory effect is caused by its ability to disrupt the MYB:CBP/p300 complex. MYBMIM directly binds to the KIX domain of CBP with an affinity similar to the naïve complex, causing its disassembly and reduced MYB-dependent expression of genes whose enhancers are occupied by it. NOD-scid mice engrafted with leukaemia cells treated with the peptide showed significant reduction of cancer burden, which was caused by mitochondrial apoptosis. Furthermore, ChIP analysis revealed a marked loss of the epigenetic mark H3K27ac on super-enhancers regulated by acetylation driven by $\mathrm{p} 300: \mathrm{CBP}$, and consequent reduced expression of key MYB-regulated genes such as $M Y C$ and $B C L 2^{71}$. 
MYB and paediatric low-grade gliomas (PLGGs) PLGGs typically present gene fusions, especially related to component of the MAPK pathway, such as $B R A F^{72}$. $M Y B$ rearrangements have been recently discovered in the context of whole-genome sequencing (WGS) and/or RNA-sequencing (RNA-seq) of 249 samples of PLGGs, leading to the identification of recurrent $M Y B-Q K I$ fusions in angiocentric gliomas ${ }^{73}$. MYB fused to the RNA-binding protein QKI confers oncogenic properties using three distinct mechanisms. Firstly, the alteration results in the translocation of a super enhancer located in the $3^{\prime}$ untranslated region of QKI upstream the $M Y B$ promoter, resulting in its activation. Secondly, the MYBQKI fusion protein acts as transcription factor, binding and activating the $M Y B$ promoter through a positive feedback loop. Thirdly, hemizygous loss of QKI expression caused by the rearrangement of its locus contributes to oncogenesis since it functions as a tumour-suppressor gene $^{74-76}$. Gene-set enrichment analysis (GSEA) revealed that the expression of $M Y B-Q K I$ fusion was associated with $M Y B$ signature genes ${ }^{73}$. MYB protein structure and its modifications found in tumours are fundamental for its transforming ability. In fact, as already mentioned above, full-length MYB is not endowed with a strong oncogenic activity in vitro, whereas $\mathrm{C}$-terminal truncations are required for its activation ${ }^{77}$. MYB-QKI breakpoints in $M Y B$ intron 9-15 result in C-terminal truncation and oncogenic activation of $M Y B^{73}$.

MYB and cancers of the gastrointestinal tract $80 \%$ of colorectal cancers are characterised by $M Y B$ overexpression, which is associated with tumour aggressiveness and poor prognosis ${ }^{78,79}$. MYB overexpression in colon cancer is a consequence of mutations in intron 1 regulatory sequence $^{80}$. Given the broad presence of the oncoprotein in this cancer, investigators in the Australian Peter MacCallum Cancer Centre engineered a vaccine against the MYB antigen called TetMYB. It is composed of an inactivated MYB protein flanked by the tetanus toxin $\mathrm{T}$ cell epitopes cloned into the pVAX1 plasmid vector. The immunotherapeutic role of the pVAX1-Tet-human MYB DNA vaccine was investigated in colon and adenoid cystic carcinoma (ACC) patients, also in combination with the anti-PD-1 antibody BGB-A317 to assess safety and maximum tolerated dose (MTD) in a first-in-human clinical trial ${ }^{81}$. This approach should overcome limitations caused by epitope/MHC restriction when targeting an endogenous antigen, as its application will not depend upon a need to match the patient's MHC subtype. The trial, if successful, could pave the way for vaccine treatment not only of colorectal cancers or ACC, but also other $M Y B$-expressing cancers. This clinical trial is based upon preclinical studies of the same Australian group in mice transplanted with MC38 colon adenocarcinoma cells expressing high levels of $M Y B$. Breaking peripheral tolerance with the vaccine strategy enhanced anti-tumour immunity mediated by both CD4+ and CD8+ T cells, without insurgence of autoimmunity, causing a significant suppression of MC38 cancer growth $^{78} . M Y B$ alterations have been also observed in pancreatic cancer, where it has been shown to interact with genes required for proliferation, survival and metastasis $^{82}$.

MYB and breast cancer MYB has been found bound to more than 10,000 promoters in MCF-7 breast cancer cells and recognised as a key activator of downstream targets, including genes involved in cancer progression and metastasis, such as cyclooxygenase-2 (COX-2), BCL2, BCLXL, JUN, KLF4, NANOG, MYC, and CXCR4 $4^{19}$. Breast cancer is a heterogeneous disease with a clinical outcome strictly determined by molecular profiles ${ }^{83,84}$. Over $70 \%$ of human breast cancers are oestrogen receptor-positive $(\mathrm{ER}+)$ and express $M Y B^{85}$. Gonda and colleagues reported for the first time that inhibition of $M Y B$ expression severely impairs the proliferation of ER+, but not ER-, breast cancer cell lines $^{37}$. The relationship between $M Y B$ and ER is also indicated by the expression of $M Y B$ in normal, ER+ murine mammary epithelial cells, suggesting a salient role of the MYB transcription factor in mammary cell proliferation and tumour development in the human and mouse systems ${ }^{37,86}$. $\mathrm{ER}+$ breast cancer benefits from endocrine therapy (ET), which can reduce local and distant cancer recurrence and mortality rate ${ }^{87,88}$. ET can be administrated as neoadjuvant, adjuvant or palliative treatment and includes aromatase inhibitors, selective ER modulators (SERMs) such as tamoxifen, and antagonists such as fulvestrant ${ }^{89}$. In ER+ve breast cancer patients, $M Y B$ expression is oestrogen-dependent, since it was observed that $M Y B$ mRNA levels were 5 -fold higher $24 \mathrm{~h}$ after stimulating breast cancer cells with beta-estradiol, suggesting a strong correlation between the proto-oncogene expression and ER status in cancer ${ }^{19}$. MYB expression in ER+ve breast cancer cells is regulated at the level of transcriptional elongation, leading to the hypothesis that CDK9 inhibitors could be used to indirectly target $M Y B$ in this cancer. Indeed, CDK9 inhibition resulted in apoptotic death of breast cancer cell lines, accompanied by dose-dependent inhibition of the $M C L-1$ gene and protein expression ${ }^{90}$. CDK9 inhibitors also impaired cell proliferation and cell cycle progression, inducing arrest at both the G1/S and G2/M phases of the cell cycle. Moreover, this led to the downregulation of MYB target genes involved in cell cycle progression such as $C C N B 1$ and $C C N E 1$, which was reversed by ectopic expression of $M Y B^{90}$.

Breast cancer patients often develop resistance to treatment. Activation of epithelial-mesenchymal transition (EMT) is a mechanism by which breast cancer cells acquire 
resistance to targeted therapies ${ }^{91}$. Micro-RNAs have been implicated in the EMT process, particularly the miR-200 family ${ }^{92,93}$. Following ectopic over expression of miR-200b/c in drug-resistant cells, $M Y B$ expression levels decreased, indicating that it is a target of miR-200s. After silencing $M Y B$ in an ER+ve breast cancer cell line refractory to tamoxifen therapy, the authors of the study observed that the EMT markers vimentin, ZEB1, and ZEB2 were downregulated, further supporting the hypothesis that $M Y B$ is involved in EMT and drug resistance in breast cancer. Indeed, as expected, breast cell line sensitivity to tamoxifen therapy was increased after inhibiting $M Y B$ expression ${ }^{94}$.

MYB and ACC Stenman and colleagues discovered the translocation $\mathrm{t}(6 ; 9)(\mathrm{q} 23 ; \mathrm{p} 23)$ as a genomic hallmark of $\mathrm{ACC}^{95}$. The translocation results in the fusion of the carboxyl-terminus of the MYB oncoprotein to five amino acids (SWYLG) encoded by the last exon of NFIB (Fig. 2) ${ }^{95,96}$. ACC is characterised by the presence of the $M Y B-N F I B$ fusion gene in $30-86 \%$ of cases, depending on the study ${ }^{97,98}$. An important consequence of chromosomal rearrangements in $\mathrm{ACC}$ is the translocation of strong enhancers near the $M Y B$, or MYBL1, locus, which activates their transcription ${ }^{99}$. Rearrangements of the $M Y B$ locus have been observed in ACCs of the breast, lungs or glands in different body locations and in cylindromas, suggesting that $M Y B$ activation is frequent in exocrine gland tumours ${ }^{98,100-102}$. Another consequence of the chromosomal translocations detected in ACC and other gland tumours is, in some cases, loss of genetic material. In this regard, Mitani and colleagues theorised that two genetic events drive ACC pathogenesis: one involves the generation of fusion genes resulting from reciprocal translocation between chromosome $6 \mathrm{q}$ and $9 \mathrm{p}$ or other partners, and the other event constitutes a loss of genetic material, denoting the presence of one or more tumour suppressor genes ${ }^{103}$. Most ACCs do not acquire a large number of genetic changes, typical of other carcinomas $^{104}$. Over half of ACC cases present chromosome 6 deletions, suggesting an important selection for these alterations in the molecular aetiology of these neoplasms. However, efforts to identify a tumour suppressor gene at these loci in ACC have been unsuccessful to date ${ }^{103,105}$.

MYB-NFIB is a putative oncoprotein, which has been shown to control ACC tumour cell proliferation and spherogenesis ${ }^{106}$. Intriguingly, the fusion gene is regulated by AKT-dependent signalling downstream of the IGF1 receptor and its expression can be downregulated by IGF1R-inhibition with linsitinib. Furthermore, EGFR and MET signalling also promote growth of ACC cells ${ }^{106}$. In line with these findings, evidence in patients or xenograft models indicate that monoclonal antibodies targeting IGF1 or EGF receptors could be effective drugs in ACCs expressing the fusion oncoprotein ${ }^{107-109}$. To investigate the implication of the MYB-NFIB fusion gene in ACC, Mitani and co-workers analysed a cohort of 123 salivary carcinomas, including primary ACCs of the salivary gland, metastatic ACCs, non-ACC salivary carcinomas, and normal salivary gland tissues ${ }^{103}$. Using RT-PCR, validated by fluorescence in situ hybridisation (FISH) analysis, they found that among 89 ACC cases (72 primary ACCs and

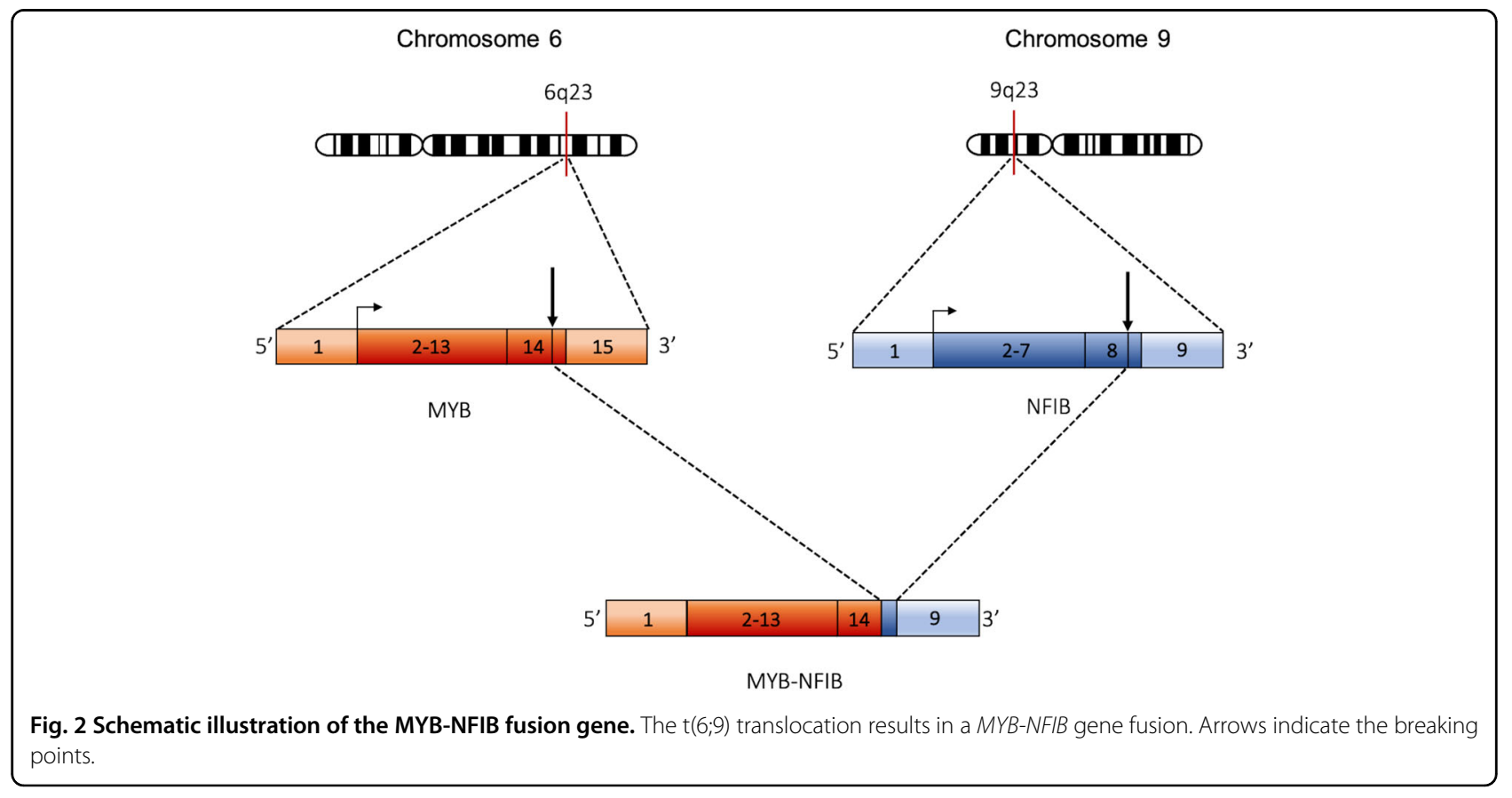


17 metastatic), 26 were positive for expression of the $M Y B-N F I B$ fusion transcript. Interestingly, none of the 34 non-ACC carcinomas were positive. In addition, 14 different fusion transcripts involving multiple exons of $M Y B$ and $N F I B$ were identified. To provide further insights on the role of $M Y B$ in this cancer, expression of the wild type or fusion $M Y B$ transcripts was quantified. Unsurprisingly, $M Y B$ expression was elevated in $M Y B-$ $N F I B$ fusion positive ACCs, probably caused by loss of the negative regulatory sequence at the $3^{\prime}$ untranslated region of $M Y B$. Interestingly, the expression of wild type $M Y B$ was elevated $>40$-fold in fusion-negative ACCs compared to non-ACC carcinomas, and only 2 -fold lower than fusionpositive ACCs. The authors concluded that whereas genomic rearrangement must be causative of $M Y B$ overexpression in fusion positive ACCs, alternative mechanisms may be responsible for $M Y B$ overexpression in fusion negative $\mathrm{ACCs}^{103}$. Thus, $M Y B$ overexpression is a frequent consequence of the MYB-NFIB fusion in glandular tumours, but can also occur via other mechanisms.

The polyether ionophore monensin was recently identified as a $M Y B$ inhibitor using a luciferase-based screen and tested on ACC cell lines derived from ACC patients. These cells were more sensitive to the anti-cancer agent than $M Y B$-expression negative, control cell lines. Monensin suppressed both $M Y B-N F I B$ mRNA and protein levels. Moreover, the compound, and related polyether ionophores, also induced differentiation and promoted apoptosis of leukaemic cell lines, suggesting that $M Y B$ inhibitors can be effective against solid and liquid malignancies ${ }^{110}$. Using a chemical screen in Zebrafish, the group of Leonard Zon have demonstrated that retinoic acid is a suppressor of MYB in ACC. All trans retinoic acid (ATRA) treatment of mice bearing patientderived ACC tumours showed reduced expression of $M Y B$ and binding of MYB at translocated enhancers. Importantly, ATRA inhibited the expression of cell cycle related, MYB-target genes. ATRA is used in the clinic for the treatment of promyelocytic leukaemia and has a known safety profile, suggesting that it will be soon used in the context of a clinical trial in ACC patients ${ }^{111}$.

Identification of actionable target genes downstream of $M Y B$ can be a reasonable alternative to avoid negative consequences caused by inactivation of the wild-type MYB transcription factor. Indeed, the potential haematologic toxicity of anti-MYB therapies could be further exacerbated in patients under regimens of chemotherapy and radiotherapy. An important gene axis regulated by MYB is the insulin growth factor and its receptor. Interestingly, insulin growth factor receptor (IGFR) signalling positively regulates $M Y B-N F I B$ in ACC, suggesting that $M Y B$ and IGFR are engaged in a feed forward loop in cancer ${ }^{112,113}$. Accordingly, it has been shown that the small molecule inhibitor Linsitinib or the therapeutic antibody Figitumumab reduce the growth of ACC tumours in mouse models and in patients, suggesting that targeting IGFR signalling could be an effective strategy in $M Y B$ overexpressing cancers ${ }^{109,112}$. In an effort to identify new MYB target genes in ACC, our group has generated retroviral vectors expressing wildtype $M Y B$ or two $M Y B-N F I B$ variants derived from ACC patients. The different $M Y B$ isoforms were ectopically expressed in immortalised breast MCF10A cells, and genes up or downregulated were identified by microarrays. GSEA revealed that $A T R / B R C A$ was the top activated downstream pathway, with a significant upregulation of $A T R$ gene expression ${ }^{43}$. ATR mRNA levels were increased in primary ACCs compared to normal salivary glands. Accordingly, the clinical ATR kinase inhibitor VX-970 caused apoptosis of primary ACC cells in vitro and significant shrinkage of ACC patient-derived xenografts. These results support the theory that acting on downstream target genes/proteins might be a worthy -and even safer-alternative to directly targeting the $M Y B$ gene itself ${ }^{43}$.

Surgery is the first line treatment for ACC, followed by cytotoxic chemotherapy and/or radiotherapy as adjuvant treatments to avoid recurrence. Unfortunately, standard treatments only provide limited benefit in advanced disease, which is usually lethal, with a high rate of recurrence and metastasis. Therefore, new and more effective treatments are urgently needed for these high-risk patients. Previous clinical trials have led to the approval of tyrosine kinase inhibitors (TKI) for the treatment of aggressive forms of solid malignancies, such as thyroid cancer refractory to radio therapy and unresectable hepatocellular carcinoma ${ }^{114,115}$. Most of the targeted tyrosine kinases are also MYB regulated, such as vascular endothelial growth factor receptors (VEGFRs), fibroblast growth factor receptors (FGFRs), the stem cell factor receptor KIT (c-KIT), FMSlike tyrosine kinase 3 (FLT3), platelet-derived growth factor receptors (PDGFRs), and the proto-oncogene RET $^{95,115-119}$. Persson and co-workers have recently shown that VEGFA, $F G F 2$, KIT and other genes encoding receptor tyrosine kinases are commonly overexpressed in ACC samples, leading to consider TKIs as credible candidates for the treatment of relapsed/metastatic ACC patients ${ }^{95}$. However, it has been observed an overall poor response in therapies against these targets in ACC, suggesting that other, more relevant $M Y B$ downstream genes should be clinically exploited in this tumour.

\section{MYBL1}

$M Y B L 1$ is predominantly expressed in the central nervous system (CNS), germinal B-lymphocytes, mammary gland ductal epithelium, and in the testis ${ }^{120,121}$. It has a key role in spermatogenesis, particularly in cell cycle 
progression of germ cells through pachynema ${ }^{121,122}$. MYBL1-null mice are viable, but exhibit growth abnormalities as well as defects in spermatogenesis and female breast development ${ }^{120}$.

\section{MYBL 1 alterations in cancer}

MYBL1 rearrangements are a hallmark of low-grade gliomas (LGGs), the commonest paediatric CNS neoplasm, arising in children and adolescents ${ }^{114,123}$. Recent molecular characterisations through WGS have led to the identification of new genetic alterations in LGGs. These studies have identified activation of the MAPK/ERK pathway caused by the duplication of the tyrosine kinase domain (TKD) of the FGFR1 gene and frequent rearrangements of the $M Y B$ family members $M Y B$ and MYBL1 in diffuse cerebral LGGs ${ }^{124}$. 8q13.1 gain was observed as a significant recurrent event in diffuse astrocytoma grade IIs. This leads to a duplication of MYBL1 and truncation of its C-terminal NRD, resulting in anchorageindependent growth of NIH-3T3 cells and tumour formation in nude mice ${ }^{125}$. MYBL1 gene amplification is a distinct alteration of the subtype IDH-wt/H3-wt of diffuse gliomas, together with TERT and BRAF mutations, EGFR and FGFR1 alterations, and other chromosomal aberrations ${ }^{126}$. Although these alterations are rare, sequencing analysis of uncommon low-grade neuro-epithelial tumours revealed that these pathogenic mutations occur at a high frequency $(78 \%)$ in this cohort ${ }^{114}$.

Patients with isomorphic diffuse glioma or astrocytoma can harbour copy number alterations of $M Y B L 1$ or $M Y B$ (13 out of 25 samples, 52\%), as assessed with RNA sequencing. Gene fusions accounted for $50 \%$ of cases ${ }^{127}$.

ACC is characterised by the chromosomal translocation $\mathrm{t}(6 ; 9)$, leading to the expression of the MYB-NFIB fusion gene $^{95}$. Although $M Y B$ is the $M Y B$ family member most often involved in this cancer, it was recently demonstrated that a subset of ACCs contains the $t(8 ; 9)$ chromosomal translocation $^{128}$. This results in the creation of a MYBL1$N F I B$ gene fusion, which probably functions in a manner similar to $M Y B-N F I B$, given the structural analogies between MYBL1 and MYB. Indeed, tumours with $M Y B$ and $M Y B L 1$ translocations display overlapping gene expression profiles and clinical outcome, suggesting that the related MYB proteins are interchangeable oncogenic drivers in ACC. The research group that identified the translocation $\mathrm{t}(8 ; 9)$, also highlighted a $\mathrm{t}(8 ; 14)$ translocation, leading to the fusion of MYBL1 to the RAD51B gene $^{128}$.

In $M Y B$ or $M Y B-N F I B$ negative subsets of breast ACC tumours, alternative genetic mechanisms of $M Y B$ activation have been demonstrated. RNA and WGS unveiled that these cancers could harbour MYBL1 rearrangements, including those between MYBL1-ACTN1 and MYBL1$N F I B^{102}$. In these rare triple negative breast cancers
(TNBC), the histological pattern was identical to the MYB-NFIB-positive, salivary gland ACCs. The MYBL1 rearrangements were confirmed at genomic level by the FISH technique. The translocation results in an in-frame chimeric transcript containing the DNA-binding and transactivating domains, encoded by exons 1-14, of $M Y B L 1$ fused to the exon 9 of NFIB. In addition, another in-frame fusion between MYBL1-ACTN1 was also detected for the first time in ACC samples. The fusion leads to loss of the C-terminus region of MYBL1 due to the fusion of exons 1-8 of MYBL1 with exons 10-21 of ACTN1 ${ }^{102}$.

Another organ in which ACC neoplasms can originate is the lung. Primary tracheobronchial ACC is one of the rarest types of lung cancer, accounting for $<1 \%$ of cases. Pei et al. analysed 7 lung ACCs, documenting that 7 out of 7 cases presented $M Y B$ or $M Y B L 1$ genes fused with $N F I B$ or, less frequently, with $R A D 51 B^{101}$. Primary cutaneous ACCs display a genetic landscape similar to those of salivary glands, showing fusions of either $M Y B$ or $M Y B L 1$ with the common partner $N F I B^{129}$.

\section{MYBL2}

$M Y B L 2$, encoding the transcription factor MYBL2, is ubiquitous and often co-expressed with other $M Y B$ members. It has been shown to regulate cell cycle progression, cell survival and differentiation being an essential component of the DREAM complex ${ }^{130-133}$. It is also a promoter of cell survival by activating antiapoptotic genes such as BIRC5 (survivin), CLU (ApoJ/clusterin) and $B C L 2^{134-137}$. MYBL2 has been shown to aid repair of DNA double-strand breaks, supporting genome stability in haematopoietic and pluripotent stem cells ${ }^{138,139}$. Expression of MYBL2 is important for both normal and transformed cell homoeostasis. This concept is supported by the early embryonic lethal phenotype of MYBL2 knockout mice, due to impaired inner cell mass formation, or suppression of cell cycle progression and cell survival in oesophageal, hepatic, colorectal, and sympathetic nervous system cancer cells in which the expression of MYBL2 has been downregulated ${ }^{140-145}$. The activity of $M Y B L 2$ is highly regulated at transcriptional and posttranscriptional levels. Cyclins and their catalytic partners, the cyclin-dependent kinases (Cdks), function as key regulators of the cell cycle ${ }^{146}$. Cyclin D1 with Cdk4 or Cdk6 has been shown to play an important role at the 'restriction point' in the G1 phase of the cell cycle before cells enter into the mitotic cycle, whereas, for the transition from $\mathrm{G} 1$ to $\mathrm{S}$ phase, cyclin E-Cdk2 complexes are the most critical, and cyclin A-Cdk2 complexes are required during $\mathrm{S}$ phase ${ }^{146}$. MYBL2 is regulated by the transcription factor E2F and required for the expression of cyclin B and $\operatorname{cdc} 2$ in $G 2 / \mathrm{M}^{147-149}$. When overexpressed, the tumour suppressor protein p53 induces Waf1/Cip1/p21 
protein-dependent cell-cycle arrest and activation of MYBL2 allows cells to escape this block, suggesting that MYBL2 acts at a later stage than Waf1/Cip1/p21 during cell-cycle progression ${ }^{150,151}$. MYBL2 is a substrate for cyclin $\mathrm{A} / \mathrm{E}-\mathrm{Cdk} 2$ kinase activity and its transcriptional activity is regulated by phosphorylation ${ }^{148,150}$.

Genes involved in the G2/M phase of the cell cycle are activated by MYBL2 switching from the repressive DREAM to the MuvB (MMB) complex ${ }^{136,152,153}$. MYBL2 is transcriptionally repressed in G1, activated by cyclin A/ Cdk2-mediated phosphorylation during S-phase, and subsequently degraded in late G2 in a ubiquitindependent manner ${ }^{147,148,154,155}$. Phosphorylation of MYBL2 occurs at Serine or Threonine residues followed by Proline ${ }^{156}$. Pin1 isomerase recognises the $\mathrm{pSer} / \mathrm{pThr}$ Pro residues altering functions of the MYBL2 protein by inducing conformation changes. Cdk-dependent phosphorylation and Pin1 isomerization induce Plk1 kinase binding to MYBL2. Plk1 phosphorylates the region of MYBL2 containing the transcriptional activation domain (TAD), suggesting that PLK1-induced modification of MYBL2 is crucially required for transcriptional activation of pro-mitotic genes ${ }^{157}$. Consistent with an important role in cell cycle progression, down-regulation of $M Y B L 2$ leads to spindle and centrosome defects, arrest in the G2/M phase of the cell cycle, failure in cytokinesis, polyploidy and apoptosis ${ }^{132,158}$.

\section{MYBL2 alterations in cancer}

The DREAM complex [DP, RB-like, E2F4 and MuvB (synMuv genes, class B)] is a master coordinator of cell cycle-dependent gene expression and the balance between repressive DREAM and activating MYB-MuvB (MMB) complexes is frequently perturbed in cancer ${ }^{159-}$ ${ }^{162}$. Increased expression of several components of the MMB complex, including MYBL2 and FOXM1, correlates with aggressive tumour features and poor prognosis $^{144,163}$. To investigate the clinical relevance of the MYBL2/FOXM1/CDK/PLK1 axis, Werwein et al. used a pan-cancer resource of expression signatures that correlate cancer gene expression and clinical prognosis data, called PRECOG ${ }^{157}$. Interestingly, among the 50 genes (and their products) analysed, 44 (including MYBL2, FOXM1, CCNA2, and PLK1) were found to be targets of DREAM-mediated repression, while 29 of them were also targets of MMB activation ${ }^{157}$. Overexpression of MYBL2 disturbs myeloid differentiation and promotes the progression of solid cancers where it is also an indicator of poor prognosis ${ }^{133,142,164-166}$. MYBL2 is frequently overexpressed in malignancies including breast cancer, non-small-cell lung cancer (NSCLC), AML, colorectal cancer, pancreatic ductal adenocarcinoma, and neuroblastoma ${ }^{167-175}$.
The molecular mechanisms causing increased expression of MYBL2 in multiple human cancers are still not fully elucidated.

MYBL2 and breast cancer Alterations of gene expression might be caused by amplification of the MYBL2 locus located in chromosome 20q13 ${ }^{176-178} .20 \mathrm{q} 13$ amplification or copy gains are common in breast cancer and are usually associated with poor prognosis ${ }^{176}$. Notably, a MYBL2 germline polymorphism causing the Serine-toGlycine amino acid change S427G is correlated to a high risk of basal-like breast cancer ${ }^{133}$. Moreover, MYBL2 overexpression was noted in HER2+/ER - and luminal B breast cancer samples, but not in luminal A or normal breast tissue, strongly suggesting a correlation between MYBL2 expression and aggressiveness of breast cancer ${ }^{177}$. A recent review explains the molecular mechanisms of $M Y B L 2$ amplification and new therapeutic opportunities in breast cancers ${ }^{179}$.

MYBL2, clear cell renal cell carcinoma (ccRCC) and NSCLC cCRCC is the most frequent renal malignancy ${ }^{180}$. MYBL2 expression could be used as a biomarker to predict patients' prognosis in this cancer. MYBL2 was found upregulated in a cohort of 530 ccRCC patients compared to healthy tissues. Of note, upregulated MYBL2 was significantly associated with age and sex of cancer patients, advanced $\mathrm{T}$ stage, lymph node and distant metastases, clinical stage and histological grade ${ }^{181}$. Moreover, a significant correlation between high MYBL2 expression and worse prognosis was established by Kaplan-Meier analysis, indicating that $M Y B L 2$ expression is an independent biomarker of progression in $\mathrm{ccRCC}^{181}$. Another neoplasia characterised by deregulation of $M Y B L 2$ is non-small-cell lung cancer (NSCLC). Analysis of MCODE clusters highlighted genes involved in "driver networks" for NSCLC, which include the transcription factors FOXM1, TFDP1, E2F4, SIN3, and MYBL2 ${ }^{182}$. A further study confirmed the potential oncogenic role of MYBL2 in NSCLC. Through chromatin immunoprecipitation (ChIP) assay, researchers identified a direct binding between MYBL2 and the gene Non-SMC CondensinIComplex Subunit $H$ (NCAPH), well-known to have oncogenic properties in lung cancer. A significant correlation between high $N C A P H$ expression and poor prognosis was confirmed, suggesting that targeting the MYBL2-regulated gene could be of potential therapeutic value in this setting ${ }^{169}$.

MYBL2 and leukaemia $M Y B L 2$ overexpression is a prognostic factor in AML, defining a subset of patients with poor prognosis ${ }^{170,183}$. This could be linked to the reduced expression of miR-30a, miR-30b and miR-30c, involved in the regulation of haematopoiesis and cell 
differentiation, which were shown to be expressed at lower levels in $M Y B L 2^{\text {high }}$ AML samples ${ }^{170,184,185}$. The strong correlation between overexpression of $M Y B L 2$ and downregulation of the miR-30 cluster suggests that the micro-RNAs antagonise the expression of $M Y B L 2$, or that the latter suppresses miRNAs expression in $\mathrm{AML}^{170}$.

A recent study published in Cell revealed a link between MYBL2 and the protein phosphatase 2A (PP2A) in leukaemia. Morita and co-workers identified a class of small molecule that they called iHAPs-improved heterocyclic activators of PP2A-able to activate a PP2A complex, which suppresses tumour progression. PP2A is an enzyme formed by different subunits; among them, PPP2R1A, PPP2CA, and PPP2R5E are strictly required for antitumor activity ${ }^{186}$. Using isotope-labelled amino acids (SILAC) and mass spectrometry analysis, substrates dephosphorylated by PP2A in the presence or absence of iHAPs were identified, among which MYBL2. The researchers were able to activate the PP2A complex, usually present in an inactive form in cancers due to the overexpression of inhibitory proteins, and observe dephosphorylation of MYBL2 on Ser241, required for transactivation of cell cycle-related genes, resulting in an irreversible growth arrest of multiple cancer cells. Thus, MYBL2 is centrally involved in cancer cell proliferation and can be indirectly targeted by small moleculemediated reactivation of the PP2A tumour suppressor $\operatorname{protein}^{186}$.

\section{Conclusions}

The MYB transcription factors are a point of convergence of numerous signalling pathways essential for multiple cellular functions, and their deregulation has been associated with aggressive behaviour of cancer cells. Reflecting the high similarity of protein structures, MYBL1, MYBL2, and MYB are all involved in the control of cell survival, proliferation and differentiation. One could hypothesise that spatio-temporal differences in gene expression during organogenesis and in pathological conditions may determine specific MYB requirements in cells. The ever-expanding number of studies reporting deregulation of MYB family members in the pathogenesis of human cancers is instigating researchers to find new and more efficient methods to target these transcription factors. Direct pharmacological inhibition of $M Y B$ or its product MYB, is emerging as a potential therapeutic strategy for both liquid and solid malignancies. Nevertheless, inhibiting MYB could potentially lead to haematopoietic toxicity, indicating that targeting downstream target genes and coactivator molecules might make more clinical sense. Further studies will be required to develop effective therapeutic interventions aiming at suppressing MYB signalling in tumours while minimising risks to patients.

\section{Acknowledgements}

Y.C. and A.S. are supported by a grant from the Oracle Cancer Trust.

Conflict of interest

The authors declare no competing interests.

\section{Publisher's note}

Springer Nature remains neutral with regard to jurisdictional claims in published maps and institutional affiliations.

Received: 16 September 2020 Revised: 5 February 2021 Accepted: 10 February 2021

Published online: 26 February 2021

\section{References}

1. Lipsick, J. S. \& Wang, D. M. Transformation by v-Myb. Oncogene $\mathbf{1 8}$ 3047-3055 (1999).

2. Roussel, M. et al. Three new types of viral oncogene of cellular origin specific for haematopoietic cell transformation. Nature 281, 452-455 (1979).

3. Hall, W. J., Bean, C. W. \& Pollard, M. Transmission of fowl leukosis through chick embryos and young chicks. Am. J. Vet. Res. 2, 272-279 (1941).

4. Boyle, W. J., Lipsick, J. S., Reddy, E. P. \& Baluda, M. A. Identification of the leukemogenic protein of avian myeloblastosis virus and of its normal cellular homologue. Proc. Natl Acad. Sci. USA 80, 2834-2838 (1983).

5. Westin, E. H. et al. Differential expression of the amv gene in human hematopoietic cells. Proc. Natl Acad. Sci. USA 79, 2194-2198 (1982).

6. Nunn, M. F., Seeburg, P. H., Moscovici, C. \& Duesberg, P. H. Tripartite structure of the avian erythroblastosis virus E26 transforming gene. Nature 306, 391-395 (1983).

7. Davidson, C. J., Tirouvanziam, R., Herzenberg, L. A. \& Lipsick, J. S. Functional evolution of the vertebrate Myb gene family: B-Myb, but neither A-Myb nor c-Myb, complements Drosophila Myb in hemocytes. Genetics 169, 215-229 (2005).

8. Lipsick, J. S. The C-MYB story-is it definitive? Proc. Natl Acad. Sci. USA 107, 17067-17068 (2010).

9. Lipsick, J. S. et al. Functional evolution of the Myb oncogene family. Blood Cells Mol. Dis. 27, 456-458 (2001).

10. Ohi, R. et al. Myb-related Schizosaccharomyces pombe cdc5p is structurally and functionally conserved in eukaryotes. Mol. Cell. Biol. 18, 4097-4108 (1998).

11. Davidson, C. J., Guthrie, E. E. \& Lipsick, J. S. Duplication and maintenance of the Myb genes of vertebrate animals. Biol. Open 2, 101-110 (2013).

12. Nomura, N. et al. Isolation of human CDNA clones of myb-related genes, Amyb and B-myb. Nucleic Acids Res. 16, 11075-11089 (1988).

13. Gewirtz, A. M. \& Calabretta, B. A c-myb antisense oligodeoxynucleotide inhibits normal human hematopoiesis in vitro. Science 242, 1303-1306 (1988).

14. O'Rourke, J. P. \& Ness, S. A. Alternative RNA splicing produces multiple forms of c-Myb with unique transcriptional activities. Mol. Cell. Biol. 28, 2091-2101 (2008).

15. Ramsay, R. G. \& Gonda, T. J. MYB function in normal and cancer cells. Nat. Rev. Cancer 8, 523-534 (2008).

16. Ogata, K. et al. Solution structure of a DNA-binding unit of Myb: a helix-turnhelix-related motif with conserved tryptophans forming a hydrophobic core. Proc. Natl Acad. Sci. USA 89, 6428-6432 (1992).

17. Biedenkapp, H., Borgmeyer, U., Sippel, A. E. \& Klempnauer, K. H. Viral myb oncogene encodes a sequence-specific DNA-binding activity. Nature 335, 835-837 (1988).

18. Ness, S. A., Marknell, A. \& Graf, T. The v-myb oncogene product binds to and activates the promyelocyte-specific mim-1 gene. Cell 59, 1115-1125 (1989).

19. Quintana, A. M., Liu, F., O'Rourke, J. P. \& Ness, S. A. Identification and regulation of c-Myb target genes in MCF-7 cells. BMC Cancer 11, 30 (2011).

20. Zhao, L. et al. Integrated genome-wide chromatin occupancy and expression analyses identify key myeloid pro-differentiation transcription factors repressed by Myb. Nucleic Acids Res. 39, 4664-4679 (2011).

21. Dai, P. et al. CBP as a transcriptional coactivator of c-Myb. Genes Dev. 10, 528-540 (1996).

22. Oelgeschlager, M., Janknecht, R., Krieg, J., Schreek, S. \& Luscher, B. Interaction of the co-activator CBP with Myb proteins: effects on Myb-specific transactivation and on the cooperativity with NF-M. EMBO J. 15, 2771-2780 (1996). 
23. Oelgeschlager, M., Kowenz-Leutz, E., Schreek, S., Leutz, A. \& Luscher, B. Tumorigenic N-terminal deletions of c-Myb modulate DNA binding, transactivation, and cooperativity with C/EBP. Oncogene 20, 7420-7424 (2001).

24. Mink, S., Kerber, U. \& Klempnauer, K. H. Interaction of C/EBPbeta and v-Myb is required for synergistic activation of the mim-1 gene. Mol. Cell. Biol. 16, 1316-1325 (1996).

25. Shapiro, L. H. Myb and Ets proteins cooperate to transactivate an early myeloid gene. J. Biol. Chem. 270, 8763-8771 (1995).

26. Bartunek, P., Kralova, J., Blendinger, G., Dvorak, M. \& Zenke, M. GATA-1 and cmyb crosstalk during red blood cell differentiation through GATA-1 binding sites in the c-myb promoter. Oncogene 22, 1927-1935 (2003).

27. Mansour, M. R. et al. Oncogene regulation. An oncogenic super-enhancer formed through somatic mutation of a noncoding intergenic element. Science 346, 1373-1377 (2014).

28. Mucenski, M. L. et al. A functional c-myb gene is required for normal murine fetal hepatic hematopoiesis. Cell 65, 677-689 (1991)

29. Stadhouders, R. et al. HBS1L-MYB intergenic variants modulate fetal hemoglobin via long-range MYB enhancers. J. Clin. Investig. 124, 1699-1710 (2014).

30. Jiang, J. et al. CMYB is involved in the regulation of fetal hemoglobin production in adults. Blood 108, 1077-1083 (2006).

31. Gautam, S. et al. The transcription factor c-Myb regulates CD8(+) T cell stemness and antitumor immunity. Nat. Immunol. 20, 337-349 (2019).

32. Thomas, M. D., Kremer, C. S., Ravichandran, K. S., Rajewsky, K. \& Bender, T. P. cMyb is critical for B cell development and maintenance of follicular B cells. Immunity 23, 275-286 (2005).

33. Kastan, M. B., Slamon, D. J. \& Civin, C. I. Expression of protooncogene c-myb in normal human hematopoietic cells. Blood 73, 1444-1451 (1989).

34. Ess, K. C., Witte, D. P., Bascomb, C. P. \& Aronow, B. J. Diverse developing mouse lineages exhibit high-level c-Myb expression in immature cells and loss of expression upon differentiation. Oncogene 18, 1103-1111 (1999).

35. Malaterre, J. et al. c-Myb is required for neural progenitor cell proliferation and maintenance of the neural stem cell niche in adult brain. Stem Cells $\mathbf{2 6}$, 173-181 (2008).

36. Malaterre, J. et al. c-Myb is required for progenitor cell homeostasis in colonic crypts. Proc. Natl Acad. Sci. USA 104, 3829-3834 (2007).

37. Drabsch, Y. et al. Mechanism of and requirement for estrogen-regulated MYB expression in estrogen-receptor-positive breast cancer cells. Proc. Natl Acad. Sci. USA 104, 13762-13767 (2007).

38. Nakata, Y. et al. c-Myb contributes to G2/M cell cycle transition in human hematopoietic cells by direct regulation of cyclin B1 expression. Mol. Cell. Biol. 27, 2048-2058 (2007)

39. Pilkinton, M., Sandoval, R., Song, J., Ness, S. A. \& Colamonici, O. R. Mip/LIN-9 regulates the expression of $\mathrm{B}-\mathrm{Myb}$ and the induction of cyclin A, cyclin B, and CDK1. J. Biol. Chem. 282, 168-175 (2007).

40. Lei, W., Liu, F. \& Ness, S. A. Positive and negative regulation of c-Myb by cyclin D1, cyclin-dependent kinases, and p27 Kip1. Blood 105, 3855-3861 (2005).

41. Nicolaides, N. C., Gualdi, R., Casadevall, C., Manzella, L. \& Calabretta, B. Positive autoregulation of c-myb expression via Myb binding sites in the $5^{\prime}$ flanking region of the human c-myb gene. Mol. Cell. Biol. 11, 6166-6176 (1991).

42. Ku, D. H. et al. c-myb transactivates cdc2 expression via Myb binding sites in the $5^{\prime}$-flanking region of the human cdc2 gene. J. Biol. Chem. 268 2255-2259 (1993).

43. Andersson, M. K. et al. ATR is a MYB regulated gene and potential therapeutic target in adenoid cystic carcinoma. Oncogenesis 9, 5 (2020).

44. Clappier, E. et al. The C-MYB locus is involved in chromosomal translocation and genomic duplications in human T-cell acute leukemia (T-ALL), the translocation defining a new T-ALL subtype in very young children. Blood 110, 1251-1261 (2007).

45. Okada, M. et al. c-myb gene analysis in T-cell malignancies with del(6q). Cancer Genet. Cytogenet. 48, 229-236 (1990).

46. Torelli, G. et al. Expression of c-myb protooncogene and other cell cyclerelated genes in normal and neoplastic human colonic mucosa. Cancer Res. 47, 5266-5269 (1987).

47. Thompson, M. A., Flegg, R., Westin, E. H. \& Ramsay, R. G. Microsatellite deletions in the c-myb transcriptional attenuator region associated with over-expression in colon tumour cell lines. Oncogene 14, 1715-1723 (1997).

48. Li, Y. et al. c-Myb enhances breast cancer invasion and metastasis through the Wnt/beta-Catenin/Axin2 pathway. Cancer Res. 76, 3364-3375 (2016).

49. Lahortiga, I. et al. Duplication of the MYB oncogene in T cell acute lymphoblastic leukemia. Nat. Genet. 39, 593-595 (2007).
50. Quelen, C. et al. Identification of a transforming MYB-GATA1 fusion gene in acute basophilic leukemia: a new entity in male infants. Blood 117, 5719-5722 (2011).

51. Belloni, E. et al. In vivo expression of an aberrant MYB-GATA1 fusion induces leukemia in the presence of GATA1 reduced levels. Leukemia 25, 733-736 (2011).

52. Ducassou, S. et al. MYB-GATA1 fusion promotes basophilic leukaemia: involvement of interleukin-33 and nerve growth factor receptors. J. Pathol. 242, 347-357 (2017)

53. Mager, L. F. et al. IL-33 signaling contributes to the pathogenesis of myeloproliferative neoplasms. J. Clin. Investig. 125, 2579-2591 (2015).

54. Bailly, R. A. et al. DNA-binding and transcriptional activation properties of the EWS-FLI-1 fusion protein resulting from the $t(11 ; 22)$ translocation in Ewing sarcoma. Mol. Cell. Biol. 14, 3230-3241 (1994).

55. Eliazer, S., Spencer, J., Ye, D., Olson, E. \& Ilaria, R. L. Jr. Alteration of mesodermal cell differentiation by EWS/FLI-1, the oncogene implicated in Ewing's sarcoma. Mol. Cell. Biol. 23, 482-492 (2003).

56. Schoch, $C$. et al. Twenty-three cases of acute lymphoblastic leukemia with translocation $\mathrm{t}(4 ; 11)(\mathrm{q} 21 ; \mathrm{q} 23)$ : the implication of additional chromosomal aberrations. Ann. Hematol. 70, 195-201 (1995).

57. Schwartz, J. C., Cech, T. R. \& Parker, R. R. Biochemical properties and biological functions of FET proteins. Annu. Rev. Biochem. 84, 355-379 (2015).

58. Pierini, T. et al. MYB deregulation from a EWSR1-MYB fusion at leukemic evolution of a JAK2 (V617F) positive primary myelofibrosis. Mol. Cytogenet. 9, 68 (2016).

59. Yamamoto, J. F. \& Goodman, M. T. Patterns of leukemia incidence in the United States by subtype and demographic characteristics, 1997-2002. Cancer Causes Control 19, 379-390 (2008).

60. Rowe, J. M. Will new agents impact survival in AML? Best. Pract. Res. Clin. Haematol. 32, 101094 (2019).

61. Taga, T., Tomizawa, D., Takahashi, H. \& Adachi, S. Acute myeloid leukemia in children: current status and future directions. Pediatr. Int. 58, 71-80 (2016).

62. Estey, E. H. Acute myeloid leukemia: 2019 update on risk-stratification and management. Am. J. Hematol. 93, 1267-1291 (2018).

63. Huret, J. L., Dessen, P. \& Bernheim, A. An atlas of chromosomes in hematological malignancies. Example: 11q23 and MLL partners. Leukemia 15, 987-989 (2001).

64. Meyer, $\mathrm{C}$. et al. The MLL recombinome of acute leukemias. Leukemia 20, 777-784 (2006).

65. Hess, J. L. et al. c-Myb is an essential downstream target for homeoboxmediated transformation of hematopoietic cells. Blood 108, 297-304 (2006).

66. Pattabiraman, D. R. et al. Interaction of c-Myb with p300 is required for the induction of acute myeloid leukemia (AML) by human AML oncogenes. Blood 123, 2682-2690 (2014).

67. Uttarkar, S. et al. Targeting acute myeloid leukemia with a small molecule inhibitor of the Myb/p300 interaction. Blood 127, 1173-1182 (2016).

68. Uttarkar, S. et al. Naphthol AS-E phosphate inhibits the activity of the transcription factor Myb by blocking the interaction with the KIX domain of the coactivator p300. Mol. Cancer Ther. 14, 1276-p1285 (2015).

69. Walf-Vorderwulbecke, V. et al. Targeting acute myeloid leukemia by druginduced C-MYB degradation. Leukemia 32, 882-889 (2018).

70. Uttarkar, S. et al. Small-molecule disruption of the Myb/p300 cooperation targets acute myeloid leukemia cells. Mol. Cancer Ther. 15, 2905-2915 (2016).

71. Ramaswamy, K. et al. Peptidomimetic blockade of MYB in acute myeloid leukemia. Nat. Commun. 9, 110 (2018).

72. Pfister, S. et al. BRAF gene duplication constitutes a mechanism of MAPK pathway activation in low-grade astrocytomas. J. Clin. Investig. 118, 1739-1749 (2008).

73. Bandopadhayay, P. et al. MYB-QKI rearrangements in angiocentric glioma drive tumorigenicity through a tripartite mechanism. Nat. Genet. 48, 273-282 (2016).

74. Yang, G. et al. RNA-binding protein quaking, a critical regulator of colon epithelial differentiation and a suppressor of colon cancer. Gastroenterology 138, 231-240 e231-235 (2010).

75. Mulholland, P. J. et al. Genomic profiling identifies discrete deletions associated with translocations in glioblastoma multiforme. Cell Cycle 5, 783-791 (2006).

76. Ichimura, K. et al. Small regions of overlapping deletions on 6q26 in human astrocytic tumours identified using chromosome 6 tile path array-CGH. Oncogene 25, 1261-1271 (2006). 
77. Gonda, T. J., Buckmaster, C. \& Ramsay, R. G. Activation of c-myb by carboxyterminal truncation: relationship to transformation of murine haemopoietic cells in vitro. EMBO J. 8, 1777-1783 (1989)

78. Williams, B. B. et al. Induction of T cell-mediated immunity using a c-Myb DNA vaccine in a mouse model of colon cancer. Cancer Immunol. Immunother. 57, 1635-1645 (2008).

79. Ramsay, R. G. et al. Myb expression is higher in malignant human colonic carcinoma and premalignant adenomatous polyps than in normal mucosa. Cell Growth Differ. 3, 723-730 (1992).

80. Hugo, $\mathrm{H}$. et al. Mutations in the MYB intron I regulatory sequence increase transcription in colon cancers. Genes Chromosomes Cancer 45, 1143-1154 (2006)

81. Pham, T. et al. First-in-human phase I clinical trial of a combined immune modulatory approach using TetMYB vaccine and Anti-PD-1 antibody in patients with advanced solid cancer including colorectal or adenoid cystic carcinoma: The MYPHISMO study protocol (NCT03287427). Contemp. Clin. Trials Commun. 16, 100409 (2019).

82. Srivastava, S. K. et al. MYB is a novel regulator of pancreatic tumour growth and metastasis. Br. J. Cancer 113, 1694-1703 (2015)

83. Vuong, D., Simpson, P. T., Green, B., Cummings, M. C. \& Lakhani, S. R. Molecular classification of breast cancer. Virchows Arch. 465, 1-14 (2014).

84. Goldhirsch, A. et al. Personalizing the treatment of women with early breast cancer: highlights of the St Gallen International Expert Consensus on the Primary Therapy of Early Breast Cancer 2013. Ann. Oncol. 24, 2206-2223 (2013).

85. Yang, R. M. et al. MYB regulates the DNA damage response and components of the homology-directed repair pathway in human estrogen receptorpositive breast cancer cells. Oncogene 38, 5239-5249 (2019).

86. Miao, R. Y. et al. MYB is essential for mammary tumorigenesis. Cancer Res. 71, 7029-7037 (2011).

87. Early Breast Cancer Trialists' Collaborative G. et al. Relevance of breast cancer hormone receptors and other factors to the efficacy of adjuvant tamoxifen: patient-level meta-analysis of randomised trials. Lancet 378, 771-784 (2011)

88. Early Breast Cancer Trialists' Collaborative G. Effects of chemotherapy and hormonal therapy for early breast cancer on recurrence and 15-year survival: an overview of the randomised trials. Lancet 365, 1687-1717 (2005).

89. Early Breast Cancer Trialists' Collaborative G. Aromatase inhibitors versus tamoxifen in early breast cancer: patient-level meta-analysis of the randomised trials. Lancet 386, 1341-1352 (2015).

90. Mitra, P., Yang, R. M., Sutton, J., Ramsay, R. G. \& Gonda, T. J. CDK9 inhibitors selectively target estrogen receptor-positive breast cancer cells through combined inhibition of MYB and MCL-1 expression. Oncotarget 7, 9069-9083 (2016).

91. Ward, A. et al. Re-expression of microRNA-375 reverses both tamoxifen resistance and accompanying EMT-like properties in breast cancer. Oncogene 32, 1173-1182 (2013)

92. Korpal, M., Lee, E. S., Hu, G. \& Kang, Y. The miR-200 family inhibits epithelial-mesenchymal transition and cancer cell migration by direct targeting of E-cadherin transcriptional repressors ZEB1 and ZEB2. J. Biol. Chem. 283, 14910-14914 (2008).

93. Park, S. M., Gaur, A. B., Lengyel, E. \& Peter, M. E. The miR-200 family determines the epithelial phenotype of cancer cells by targeting the E-cadherin repressors ZEB1 and ZEB2. Genes Dev. 22, 894-907 (2008)

94. Gao, Y., Zhang, W., Liu, C. \& Li, G. miR-200 affects tamoxifen resistance in breast cancer cells through regulation of MYB. Sci. Rep. 9, 18844 (2019).

95. Persson, M. et al. Recurrent fusion of MYB and NFIB transcription factor genes in carcinomas of the breast and head and neck. Proc. Natl Acad. Sci. USA 106, 18740-18744 (2009).

96. Brill, L. B. II et al. Analysis of MYB expression and MYB-NFIB gene fusions in adenoid cystic carcinoma and other salivary neoplasms. Mod. Pathol. 24, 1169-1176 (2011).

97. Togashi, Y. et al. MYB and MYBL1 in adenoid cystic carcinoma: diversity in the mode of genomic rearrangement and transcripts. Mod. Pathol. 31, 934-946 (2018)

98. Magers, M. J. et al. MYB-NFIB gene fusion in prostatic basal cell carcinoma: clinicopathologic correlates and comparison with basal cell adenoma and florid basal cell hyperplasia. Mod. Pathol. 32, 1666-1674 (2019).

99. Drier, Y. et al. An oncogenic MYB feedback loop drives alternate cell fates in adenoid cystic carcinoma. Nat. Genet. 48, 265-272 (2016).

100. Fehr, A. et al. The MYB-NFIB gene fusion-a novel genetic link between adenoid cystic carcinoma and dermal cylindroma. J. Pathol. 224, 322-327 (2011)
101. Pei, J. et al. Detecting MYB and MYBL1 fusion genes in tracheobronchial adenoid cystic carcinoma by targeted RNA-sequencing. Mod. Pathol. 32 , 1416-1420 (2019).

102. Kim, J. et al. MYBL1 rearrangements and MYB amplification in breast adenoid cystic carcinomas lacking the MYB-NFIB fusion gene. J. Pathol. 244, 143-150 (2018).

103. Mitani, Y. et al. Comprehensive analysis of the MYB-NFIB gene fusion in salivary adenoid cystic carcinoma: Incidence, variability, and clinicopathologic significance. Clin. Cancer Res. 16, 4722-4731 (2010).

104. Ho, A. S. et al. The mutational landscape of adenoid cystic carcinoma. Nat Genet. 45, 791-798 (2013).

105. Rutherford, S., Yu, Y., Rumpel, C. A., Frierson, H. F. Jr. \& Moskaluk, C. A. Chromosome 6 deletion and candidate tumor suppressor genes in adenoid cystic carcinoma. Cancer Lett. 236, 309-317 (2006).

106. Andersson M. K., Afshari M. K., Andren Y., Wick M. J., \& Stenman G. Targeting the oncogenic transcriptional regulator MYB in adenoid cystic carcinoma by inhibition of IGF1R/AKT signaling. J. Natl Cancer Inst. 109, (2017).

107. Morelli, M. P. et al. Prioritizing phase I treatment options through preclinical testing on personalized tumorgraft. J. Clin. Oncol. 30, e45-e48 (2012).

108. Mahadevan, D. et al. Phase $1 \mathrm{~b}$ study of safety, tolerability and efficacy of R1507, a monoclonal antibody to IGF-1R in combination with multiple standard oncology regimens in patients with advanced solid malignancies. Cancer Chemother. Pharm. 73, 467-473 (2014).

109. Calvo, E. et al. A Phase I clinical trial and independent patient-derived xenograft study of combined targeted treatment with dacomitinib and figitumumab in advanced solid tumors. Clin. Cancer Res. 23, 1177-1185 (2017).

110. Yusenko, M. V. et al. Monensin, a novel potent MYB inhibitor, suppresses proliferation of acute myeloid leukemia and adenoid cystic carcinoma cells. Cancer Lett. 479, 61-70 (2020).

111. Mandelbaum, J. et al. Zebrafish blastomere screen identifies retinoic acid suppression of <ovid:i>MYB</ovid:i> in adenoid cystic carcinoma. J. Exp. Med. 215, 2673-2685 (2018).

112. Andersson, K. M., Afshari, M. K., Andrén, Y., Wick, M. J. \& Stenman, G. Targeting the oncogenic transcriptional regulator MYB in adenoid cystic carcinoma by inhibition of IGF1R/AKT signaling. J. Natl Cancer Inst. 109, djx017 (2017).

113. Reiss, $\mathrm{K}$. et al. The protooncogene c-myb increases the expression of insulinlike growth factor 1 and insulin-like growth factor 1 receptor messenger RNAs by a transcriptional mechanism. Cancer Res. 51, 5997-6000 (1991).

114. Qaddoumi, I. et al. Genetic alterations in uncommon low-grade neuroepithelial tumors: BRAF, FGFR1, and MYB mutations occur at high frequency and align with morphology. Acta Neuropathol. 131, 833-845 (2016).

115. Locati, L. D. et al. A phase II study of sorafenib in recurrent and/or metastatic salivary gland carcinomas: translational analyses and clinical impact. Eur. J. Cancer 69, 158-165 (2016).

116. Tchekmedyian, V. et al. Phase II study of lenvatinib in patients with progressive, recurrent or metastatic adenoid cystic carcinoma. J. Clin. Oncol. 37, 1529-1537 (2019).

117. Okamoto, K et al. Antitumor activities of the targeted multi-tyrosine kinase inhibitor lenvatinib (E7080) against RET gene fusion-driven tumor models. Cancer Lett. 340, 97-103 (2013).

118. Lutwyche, J. K., Keough, R. A., Hunter, J., Coles, L. S. \& Gonda, T. J. DNA binding-independent transcriptional activation of the vascular endothelia growth factor gene (VEGF) by the Myb oncoprotein. Biochem. Biophys. Res. Commun. 344, 1300-1307 (2006).

119. Ferrao, P., Gonda, T. J. \& Ashman, L. K. Expression of constitutively activated human C-Kit in Myb transformed early myeloid cells leads to factor independence, histiocytic differentiation, and tumorigenicity. Blood $\mathbf{9 0}$, 4539-4552 (1997).

120. Toscani, A. et al. Arrest of spermatogenesis and defective breast development in mice lacking A-myb. Nature 386, 713-717 (1997).

121. Mettus, R. V. et al. Murine A-myb: evidence for differential splicing and tissuespecific expression. Oncogene 9, 3077-3086 (1994).

122. Bolcun-Filas, E. et al. A-MYB (MYBL1) transcription factor is a master regulator of male meiosis. Development 138, 3319-3330 (2011).

123. Armstrong, G. T. et al. Survival and long-term health and cognitive outcomes after low-grade glioma. Neuro Oncol. 13, 223-234 (2011).

124. Zhang, J. et al. Whole-genome sequencing identifies genetic alterations in pediatric low-grade gliomas. Nat. Genet. 45, 602-612 (2013).

125. Ramkissoon, L. A. et al. Genomic analysis of diffuse pediatric low-grade gliomas identifies recurrent oncogenic truncating rearrangements in the transcription factor MYBL1. Proc. Natl Acad. Sci. USA 110, 8188-8193 (2013). 
126. Ellison, D. W. et al. CIMPACT-NOW update 4: diffuse gliomas characterized by MYB, MYBL1, or FGFR1 alterations or BRAF(V600E) mutation. Acta Neuropathol. 137, 683-687 (2019)

127. Wefers, A. K. et al. Isomorphic diffuse glioma is a morphologically and molecularly distinct tumour entity with recurrent gene fusions of MYBL1 or MYB and a benign disease course. Acta Neuropathol. 139, 193-209 (2020).

128. Brayer, K. J., Frerich, C. A., Kang, H. \& Ness, S. A. Recurrent fusions in MYB and MYBL1 define a common, transcription factor-driven oncogenic pathway in salivary gland adenoid cystic carcinoma. Cancer Discov. 6, 176-187 (2016).

129. Kyrpychova, L. et al. Small subset of adenoid cystic carcinoma of the skin is associated with alterations of the MYBL1 gene similar to their extracutaneous counterparts. Am. J. Dermatopathol. 40, 721-726 (2018).

130. Iness, A. N. et al. The cell cycle regulatory DREAM complex is disrupted by high expression of oncogenic B-Myb. Oncogene 38, 1080-1092 (2019).

131. Sala, A. \& Calabretta, B. Regulation of BALB/C $3 T 3$ fibroblast proliferation by Bmyb is accompanied by selective activation of cdc2 and cyclin D1 expression. Proc. Natl Acad. Sci. USA 89, 10415-10419 (1992).

132. Santilli, G. et al. Temperature-dependent modification and activation of BMYB: implications for cell survival. J. Biol. Chem. 280, 15628-15634 (2005).

133. Thorner, A. R. et al. In vitro and in vivo analysis of B-Myb in basal-like breast cancer. Oncogene 28, 742-751 (2009).

134. Cervellera, M. et al. Direct transactivation of the anti-apoptotic gene apolipoprotein J (clusterin) by B-MYB. J. Biol. Chem. 275, 21055-21060 (2000).

135. Lang, G., Gombert, W. M. \& Gould, H. J. A transcriptional regulatory element in the coding sequence of the human $\mathrm{BCl}-2$ gene. Immunology 114, 25-36 (2005).

136. Knight, A. S., Notaridou, M. \& Watson, R. J. A Lin-9 complex is recruited by BMyb to activate transcription of G2/M genes in undifferentiated embryonal carcinoma cells. Oncogene 28, 1737-1747 (2009).

137. Grassilli, E., Salomoni, P., Perrotti, D., Franceschi, C. \& Calabretta, B. Resistance to apoptosis in CTLL-2 cells overexpressing B-Myb is associated with B-Mybdependent bcl-2 induction. Cancer Res. 59, 2451-2456 (1999).

138. Lorvellec, M. et al. B-Myb is critical for proper DNA duplication during an unperturbed $S$ phase in mouse embryonic stem cells. Stem Cells $\mathbf{2 8}$ 1751-1759 (2010).

139. Garcia, P. \& Frampton, J. The transcription factor B-Myb is essential for Sphase progression and genomic stability in diploid and polyploid megakaryocytes. J. Cell Sci. 119, 1483-1493 (2006).

140. Tanaka, Y., Patestos, N. P., Maekawa, T. \& Ishii, S. B-myb is required for inner cell mass formation at an early stage of development. J. Biol. Chem. 274, 28067-28070 (1999).

141. Gualdrini, F. et al. Addiction of MYCN amplified tumours to B-MYB underscores a reciprocal regulatory loop. Oncotarget 1, 278-288 (2010).

142. Qin, H. et al. Prognostic implications and oncogenic roles of MYBL2 protein expression in esophageal squamous-cell carcinoma. Onco Targets Ther. 12, 1917-1927 (2019).

143. Calvisi, D. F. et al. Activation of $\mathrm{V}-\mathrm{Myb}$ avian myeloblastosis viral oncogene homolog-like2 (MYBL2)-LIN9 complex contributes to human hepatocarcinogenesis and identifies a subset of hepatocellular carcinoma with mutant p53. Hepatology 53, 1226-1236 (2011).

144. Wei, T. et al. YAP-dependent induction of UHMK1 supports nuclear enrichment of the oncogene MYBL2 and proliferation in liver cancer cells. Oncogene 38, 5541-5550 (2019).

145. Lee, Y. J. et al. Ginkgetin induces G2-phase arrest in HCT116 colon cancer cells through the modulation of bMyb and miRNA34a expression. Int. J. Oncol. 51, 1331-1342 (2017).

146. MacLachlan, T. K., Sang, N. \& Giordano, A. Cyclins, cyclin-dependent kinases and cdk inhibitors: implications in cell cycle control and cancer. Crit. Rev. Eukaryot. Gene Expr. 5, 127-156 (1995).

147. Lam, E. W. \& Watson, R. J. An E2F-binding site mediates cell-cycle regulated repression of mouse B-myb transcription. EMBO J. 12, 2705-2713 (1993).

148. Sala, A. et al. Activation of human B-MYB by cyclins. Proc. Natl Acad. Sci. USA 94, 532-536 (1997)

149. Zhu, W., Giangrande, P. H. \& Nevins, J. R. E2Fs link the control of G1/S and G2/ M transcription. EMBO J. 23, 4615-4626 (2004).

150. Ziebold, U., Bartsch, O., Marais, R., Ferrari, S. \& Klempnauer, K. H. Phosphorylation and activation of B-Myb by cyclin A-Cdk2. Curr. Biol. 7, 253-260 (1997).

151. Lin, D. et al. Constitutive expression of B-myb can bypass p53-induced Waf1/ Cip1-mediated G1 arrest. Proc. Natl Acad. Sci. USA 91, 10079-10083 (1994).

152. Litovchick, L. et al. Evolutionarily conserved multisubunit RBL2/p130 and E2F4 protein complex represses human cell cycle-dependent genes in quiescence. Mol. Cell 26, 539-551 (2007).
153. Schmit, F. et al. LINC, a human complex that is related to pRB-containing complexes in invertebrates regulates the expression of G2/M genes. Cell Cycle 6, 1903-1913 (2007).

154. Zwicker, J., Liu, N., Engeland, K., Lucibello, F. C. \& Muller, R. Cell cycle regulation of E2F site occupation in vivo. Science 271, 1595-1597 (1996).

155. Robinson, C. et al. Cell-cycle regulation of B-Myb protein expression: specific phosphorylation during the $\mathrm{S}$ phase of the cell cycle. Oncogene 12, 1855-1864 (1996).

156. Bartsch, O., Horstmann, S., Toprak, K., Klempnauer, K. H. \& Ferrari, S. Identification of cyclin AVCdk2 phosphorylation sites in B-Myb. Eur. J. Biochem. 260 384-391 (1999).

157. Werwein, E., Cibis, H., Hess, D. \& Klempnauer, K. H. Activation of the oncogenic transcription factor B-Myb via multisite phosphorylation and prolyl cis/ trans isomerization. Nucleic Acids Res. 47, 103-121 (2019).

158. Tarasov, K. V. et al. B-MYB is essential for normal cell cycle progression and chromosomal stability of embryonic stem cells. PLOS ONE 3, e2478 (2008).

159. Sadasivam, S., Duan, S. \& DeCaprio, J. A. The MuvB complex sequentially recruits B-Myb and FoxM1 to promote mitotic gene expression. Genes Dev. 26, 474-489 (2012)

160. Wolter, P., Hanselmann, S., Pattschull, G., Schruf, E. \& Gaubatz, S. Central spindle proteins and mitotic kinesins are direct transcriptional targets of MuvB, B-MYB and FOXM1 in breast cancer cell lines and are potential targets for therapy. Oncotarget 8, 11160-11172 (2017).

161. Fischer, M. \& Müller, G. A. Cell cycle transcription control: DREAM/MuvB and RB-E2F complexes. Crit. Rev. Biochem. Mol. Biol. 52, 638-662 (2017).

162. Iness, A. N. \& Litovchick, L. MuvB: a key to cell cycle control in ovarian cancer. Front. Oncol. 8, 223 (2018).

163. Liao, G. B. et al. Regulation of the master regulator FOXM1 in cancer. Cell Commun. Signal. 16, 57 (2018).

164. Engelhard, A., Campbell, K. \& Calabretta, B. B-myb alters the response of myeloid precursor cells to G-CSF. Exp. Cell Res. 254, 153-162 (2000).

165. Guan, Z., Cheng, W., Huang, D. \& Wei, A. High MYBL2 expression and transcription regulatory activity is associated with poor overall survival in patients with hepatocellular carcinoma. Curr. Res. Transl. Med. 66, 27-32 (2018).

166. Pattschull, G. et al. The Myb-MuvB complex is required for YAP-dependent transcription of mitotic genes. Cell Rep. 27, 3533-3546 e3537 (2019).

167. Chen, J. \& Chen, X. MYBL2 is targeted by miR-143-3p and regulates breast cancer cell proliferation and apoptosis. Oncol. Res. 26, 913-922 (2018).

168. Jin, Y. et al. B-Myb is up-regulated and promotes cell growth and motility in non-small cell lung cancer. Int. J. Mol. Sci. 18, 860 (2017).

169. Xiong, Y. C., Wang, J., Cheng, Y., Zhang, X. Y. \& Ye, X. Q. Overexpression of MYBL2 promotes proliferation and migration of non-small-cell lung cancer via upregulating NCAPH. Mol. Cell. Biochem. 468, 185-193 (2020).

170. Fuster, O. et al. Adverse prognostic value of MYBL2 overexpression and association with microRNA-30 family in acute myeloid leukemia patients. Leuk. Res. 37, 1690-1696 (2013).

171. Heinrichs, S. et al. MYBL2 is a sub-haploinsufficient tumor suppressor gene in myeloid malignancy. Elife 2, e00825 (2013).

172. Ren, F. et al. MYBL2 is an independent prognostic marker that has tumorpromoting functions in colorectal cancer. Am. J. Cancer Res. 5, 1542-1552 (2015).

173. Yu, R. et al. Clinicopathologic features and prognostic implications of MYBL2 protein expression in pancreatic ductal adenocarcinoma. Pathol. Res. Pract. 213, 964-968 (2017).

174. Raschella, G. et al. Expression of B-myb in neuroblastoma tumors is a poor prognostic factor independent from MYCN amplification. Cancer Res. 59, 3365-3368 (1999).

175. Raschella, G. et al. Requirement of b-myb function for survival and differentiative potential of human neuroblastoma cells. J. Biol. Chem. 270 8540-8545 (1995).

176. Shi, $H$. et al. Single nucleotide polymorphisms in the $20 q 13$ amplicon genes in relation to breast cancer risk and clinical outcome. Breast Cancer Res. Treat. 130, 905-916 (2011)

177. Tanner, M. M. et al. Frequent amplification of chromosomal region 20q12q13 in ovarian cancer. Clin. Cancer Res. 6, 1833-1839 (2000).

178. Forozan, F. et al. Comparative genomic hybridization analysis of 38 breast cancer cell lines: a basis for interpreting complementary DNA microarray data. Cancer Res. 60, 4519-4525 (2000).

179. Bayley, R., Ward, C. \& Garcia, P. MYBL2 amplification in breast cancer: Molecular mechanisms and therapeutic potential. Biochim. Biophys. Acta Rev. Cancer 1874, 188407 (2020). 
180. Ljungberg, B. et al. European association of urology guidelines on renal cell carcinoma: the 2019 update. Eur. Urol. 75, 799-810 (2019).

181. Sun, S. S., Fu, Y. \& Lin, J. Y. Upregulation of MYBL2 independently predicts a poorer prognosis in patients with clear cell renal cell carcinoma. Oncol. Lett. 19, 2765-2772 (2020).

182. Ahmed, F. Integrated network analysis reveals FOXM1 and MYBL2 as key regulators of cell proliferation in non-small cell lung cancer. Front. Oncol. 9, 1011 (2019).

183. Clarke, M. et al. MYBL2 haploinsufficiency increases susceptibility to agerelated haematopoietic neoplasia. Leukemia 27, 661-670 (2013).

184. Chen, C. Z., Li, L., Lodish, H. F. \& Bartel, D. P. MicroRNAs modulate hematopoietic lineage differentiation. Science $\mathbf{3 0 3}, 83-86$ (2004).

185. Cammarata, G. et al. Differential expression of specific microRNA and their targets in acute myeloid leukemia. Am. J. Hematol. 85, 331-339 (2010).

186. Morita, K. et al. Allosteric activators of protein phosphatase 2A display broad antitumor activity mediated by dephosphorylation of MYBL2. Cell 181, 702-715.e720 (2020).

187. Leverson, J. D. \& Ness, S. A. Point mutations in v-Myb disrupt a cyclophilincatalyzed negative regulatory mechanism. Mol. Cell 1, 203-211 (1998).

188. Introna, M. et al. Mutations in v-myb alter the differentiation of myelomonocytic cells transformed by the oncogene. Cell 63, 1289-1297 (1990).

189. Takahashi, T. et al. Inhibitory interaction of c-Myb and GATA-1 via transcriptional co-activator CBP. Oncogene 19, 134-140 (2000).

190. Rushton, J. J. \& Ness, S. A. The conserved DNA binding domain mediates similar regulatory interactions for A-Myb, B-Myb, and C-Myb transcription factors. Blood Cells Mol. Dis. 27, 459-463 (2001).

191. Bergholtz, S. et al. The highly conserved DNA-binding domains of A-, B- and c-Myb differ with respect to DNA-binding, phosphorylation and redox properties. Nucleic Acids Res. 29, 3546-3556 (2001).

192. Luscher, B., Christenson, E., Litchfield, D. W., Krebs, E. G. \& Eisenman, R. N. Myb DNA binding inhibited by phosphorylation at a site deleted during oncogenic activation. Nature 344, 517-522 (1990).

193. Cervellera, M. N. \& Sala, A. Poly(ADP-ribose) polymerase is a B-MYB coactivator. J. Biol. Chem. 275, 10692-10696 (2000).

194. Bies, J., Markus, J. \& Wolff, L. Covalent attachment of the SUMO-1 protein to the negative regulatory domain of the c-Myb transcription factor modifies its stability and transactivation capacity. J. Biol. Chem. 277, 8999-9009 (2002).

195. Sano, Y. \& Ishii, S. Increased affinity of C-Myb for CREB-binding protein (CBP) after CBP-induced acetylation. J. Biol. Chem. 276, 3674-3682 (2001).

196. Aziz, N. et al. Modulation of c-Myb-induced transcription activation by a phosphorylation site near the negative regulatory domain. Proc. Natl Acad. Sci. USA 92, 6429-6433 (1995).

197. Tomita, A. et al. c-Myb acetylation at the carboxyl-terminal conserved domain by transcriptional co-activator p300. Oncogene 19, 444-p451 (2000).

198. Frampton, J., Ramqvist, T. \& Graf, T. v-Myb of E26 leukemia virus up-regulates bcl2 and suppresses apoptosis in myeloid cells. Genes Dev. 10, 2720-2731 (1996).

199. Salomoni, P., Perrotti, D., Martinez, R., Franceschi, C. \& Calabretta, B. Resistance to apoptosis in CTLL-2 cells constitutively expressing c-Myb is associated with induction of BCL-2 expression and Myb-dependent regulation of bcl-2 promoter activity. Proc. Natl Acad. Sci. USA 94, 3296-3301 (1997).

200. Zhou, F., Zhang, L., van Laar, T., van Dam, H. \& Ten Dijke, P. GSK3beta inactivation induces apoptosis of leukemia cells by repressing the function of c-Myb. Mol. Biol. Cell 22, 3533-3540 (2011).
201. Down, C. F., Millour, J., Lam, E. W. \& Watson, R. J. Binding of FoxM1 to G2/M gene promoters is dependent upon B-Myb. Biochim. Biophys. Acta 1819, 855-862 (2012).

202. Osterloh, L. et al. The human synMuv-like protein LIN-9 is required for transcription of G2/M genes and for entry into mitosis. EMBO J. 26, 144-157 (2007).

203. Okada, M., Akimaru, H., Hou, D. X., Takahashi, T. \& Ishii, S. Myb controls G(2)/M progression by inducing cyclin $B$ expression in the Drosophila eye imaginal disc. EMBO J. 21, 675-684 (2002).

204. Bartusel, T., Schubert, S. \& Klempnauer, K. H. Regulation of the cyclin D1 and cyclin A1 promoters by B-Myb is mediated by Sp1 binding sites. Gene $\mathbf{3 5 1}$ 171-180 (2005).

205. Srivastava, S. K. et al. Myb overexpression overrides androgen depletioninduced cell cycle arrest and apoptosis in prostate cancer cells, and confers aggressive malignant traits: potential role in castration resistance. Carcinogenesis 33, 1149-1157 (2012).

206. Cheasley, D. et al. Defective Myb function ablates cyclin E1 expression and perturbs intestinal carcinogenesis. Mol. Cancer Res. 13, 1185-1196 (2015).

207. Siu, G., Wurster, A. L., Lipsick, J. S. \& Hedrick, S. M. Expression of the CD4 gene requires a Myb transcription factor. Mol. Cell. Biol. 12, 1592-1604 (1992).

208. Melotti, P., Ku, D. H. \& Calabretta, B. Regulation of the expression of the hematopoietic stem cell antigen CD34: role of c-myb. J. Exp. Med. 179 1023-1028 (1994).

209. Ma, X. P. \& Calabretta, B. DNA binding and transactivation activity of A-myb, a c-myb-related gene. Cancer Res. 54, 6512-6516 (1994).

210. Papetti, M. \& Augenlicht, L. H. MYBL2, a link between proliferation and differentiation in maturing colon epithelial cells. J. Cell. Physiol. 226, 785-791 (2011).

211. De Dominici, M. et al. Targeting CDK6 and BCL2 Exploits the "MYB Addiction" of $\mathrm{Ph}(+)$ acute lymphoblastic leukemia. Cancer Res. 78, 1097-1109 (2018).

212. Frau, M. et al. Mybl2 expression is under genetic control and contributes to determine a hepatocellular carcinoma susceptible phenotype. J. Hepatol. $\mathbf{5 5}$ $111-119$ (2011).

213. Liu, F., Lei, W., O'Rourke, J. P. \& Ness, S. A. Oncogenic mutations cause dramatic, qualitative changes in the transcriptional activity of c-Myb. Oncogene 25, 795-805 (2006)

214. Hogg, A. et al. Inactivation of a c-Myb/estrogen receptor fusion protein in transformed primary cells leads to granulocyte/macrophage differentiation and down regulation of c-kit but not c-myc or cdc2. Oncogene $\mathbf{1 5}$ 2885-2898 (1997).

215. Ratajczak, M. Z. et al. Myb and ets proteins are candidate regulators of c-kit expression in human hematopoietic cells. Blood 91, 1934-1946 (1998).

216. Dudek, H., Tantravahi, R. V., Rao, V. N., Reddy, E. S. \& Reddy, E. P. Myb and Ets proteins cooperate in transcriptional activation of the mim-1 promoter. Proc Natl Acad. Sci. USA 89, 1291-1295 (1992).

217. Wilczek, C., Chayka, O., Plachetka, A. \& Klempnauer, K. H. Myb-induced chromatin remodeling at a dual enhancer/promoter element involves noncoding ma transcription and is disrupted by oncogenic mutations of $\mathrm{v}$-myb. J. Biol. Chem. 284, 35314-35324 (2009).

218. Nakagoshi, H., Kanei-Ishii, C., Sawazaki, T., Mizuguchi, G. \& Ishii, S. Transcriptional activation of the $\mathrm{c}$-myc gene by the $\mathrm{c}-\mathrm{myb}$ and $\mathrm{B}$-myb gene products. Oncogene 7, 1233-1240 (1992). 